\title{
Pinnulariaceae (Bacillariophyceae) do rio Guaraguaçu, bacia hidrográfica litorânea paranaense, Brasil
}

\author{
Priscila Izabel Tremarin ${ }^{1,2}$, Hermes Moreira-Filho ${ }^{1}$ e Thelma Alvim Veiga Ludwig ${ }^{1}$
}

Recebido em 25/05/2009. Aceito em 6/11/2009

RESUMO - (Pinnulariaceae (Bacillariophyceae) do rio Guaraguaçu, bacia hidrográfica litorânea paranaense, Brasil). O estudo das Pinnulariaceae do rio Guaraguaçu baseou-se em 29 amostras planctônicas e perifíticas coletadas em seis estações de coleta ao longo do leito do rio. A análise qualitativa das amostras permitiu a identificação de 36 espécies, 14 variedades e uma forma taxonômica: Caloneis bacillum, C. hyalina, C. formosa, C. westii, Pinnularia acoricola, P. acrosphaeria, P. acrosphaeria f. minor, P. acuminata var. acuminata, P. acuminata var. novazealandica, P. borealis var. rectangularis, $P$. brauniana, $P$. butantanum, $P$. decrescens var. ignorata, $P$. divergens var. biconstricta, $P$. divergens var. divergens, $P$. divergens var. malayensis, $P$. divergens var. media, $P$. divergens var. mesoleptiformis, $P$. diversarea, $P$. dornii, $P$. gibba, $P$. graciloides var. latecapitata, $P$. grunowii, $P$. hartleyana var. curta, $P$. huckiae, $P$. hudsonii, P. hyalina, P. inconstans, P. latevittata, P. maculata, P. meriadiana var. parallela, P. michelcostei, P. microstauron, P. neomajor, $P$. nobilis var. regularis, $P$. oominensis, $P$. rhombarea, $P$. rostratissima var. parva, P. rumrichae, $P$. stidolphii, $P$. stoermeri, $P$. subcapitata, $P$. subgibba var. subgibba, P. subgibba var. undulata, P. sudetica, P. tabellaria, P. viridiformis, P. viridis, Pinnularia sp. 1 e Pinnularia sp.2; sendo 32 destas novos registros para o estado do Paraná.

Palavras-chave: ambiente lótico, Caloneis, estuário, Pinnularia, taxonomia

ABSTRACT - (Pinnulariaceae (Bacillariophyceae) of the Guaraguaçu River, a coastal watershed in Paraná, Brazil). The survey of Pinnulariaceae was based on 29 planktonic and periphytic samples collected at six stations in the Guaraguaçu River. The qualitative analysis of samples allowed the identification of 36 species, 14 varieties and one taxonomic form: Caloneis bacillum, C. hyalina, C. formosa, C. westii, Pinnularia acoricola, P. acrosphaeria, P. acrosphaeria f. minor, P. acuminata var. acuminata, P. acuminata var. novazealandica, P. borealis var. rectangularis, $P$. brauniana, $P$. butantanum, $P$. decrescens var. ignorata, $P$. divergens var. biconstricta, $P$. divergens var. divergens, $P$. divergens var. malayensis, $P$. divergens var. media, $P$. divergens var. mesoleptiformis, P. diversarea, P. dornii, P. gibba, P. graciloides var. latecapitata, P. grunowii, P. hartleyana var. curta, P. huckiae, $P$. hudsonii, $P$. hyalina, $P$. inconstans, $P$. latevittata, P. maculata, P. meriadiana var. parallela, P. michelcostei, P. microstauron, $P$. neomajor, $P$. nobilis var. regularis, $P$. oominensis, $P$. rhombarea, P. rostratissima var. parva, $P$. rumrichae, $P$. stidolphii, $P$. stoermeri, $P$. subcapitata, $P$. subgibba var. subgibba, $P$. subgibba var. undulata, $P$. sudetica, $P$. tabellaria, P. viridiformis, P. viridis, Pinnularia sp.1 and Pinnularia sp.2; 32 of these are new records for Parana state.

Key words: Caloneis, estuary, lotic system, Pinnularia, taxonomy

\section{Introdução}

A família Pinnulariaceae Mann é composta por indivíduos solitários que apresentam estrias de estrutura alveolada (Round et al. 1990). Abrange os gêneros Diatomella Greville, Dimidiata Hajós, Oestrupia Heiden, Pinnularia Ehrenberg e Caloneis Cleve, sendo os dois últimos comumente encontrados em ambientes continentais.

Trabalhos relevantes sobre os gêneros Pinnularia e Caloneis foram realizados, principalmente para a flora européia. Krammer \& Lange-Bertalot (1986) realizaram a primeira revisão gênero, posteriormente aprimorada por Krammer (1992; 2000) com a proposição de novos táxons e novas combinações. Para a América do Sul, destacam-se os trabalhos de Metzeltin \& Lange-Bertalot $(1998 ; 2007)$ em regiões tropicais, Rumrich et al. (2000) nos Andes e Metzeltin et al. (2005) no Uruguai.

Considerando-se o elevado número de espécies conhecidas e apesar da ocorrência freqüente em amostras estudadas, ainda há poucas publicações sobre a flora de Pinnulariceae do Brasil. Destacam-se os trabalhos de Torgan et al. (1999) que cadastraram 119 táxons infragenéricos incluídos em Pinnulariaceae para ambientes de águas continentais e estuarinos do Rio Grande do Sul, de Souza \& Moreira-Filho (1999) e de Delgado \& Souza (2007) que citaram oito e dez táxons infragenéricos de
Pinnulariaceae, respectivamente, para o centro-oeste brasileiro, abrangendo Distrito Federal e Goiás, de Costa \& Torgan (1991) que registraram sete espécies para um lago em Minas Gerais, e de Rocha \& Bicudo (2008) que encontraram 13 espécies e sete variedades em amostras do Parque Estadual das Fontes do Ipiranga, em São Paulo, além de descreverem uma nova variedade: P. brauniana var. sanctipaulensis Rocha.

No estado do Paraná, os trabalhos com maior representatividade de espécies da família Pinnulariaceae foram os de Moreira-Filho \& Momoli (1966) com 12 espécies e quatro variedades em focos larvários de anofelinos em Curitiba; Momoli (1967) com nove espécie e uma variedade de Pinnularia no estudo das diatomáceas do tanque do Senegaglia, em São José dos Pinhais; Lozovei \& Luz (1976) que encontraram 15 espécies no conteúdo estomacal de Diptera culicidae em Curitiba e arredores; Contin (1990) que estudou 31 táxons infragenéricos na região da barragem de captação de água do rio Iguaçu; Rodrigues (1991) com 14 espécies de Pinnulariaceae no estudo das lagoas do Horto Florestal de Maringá; Fürstenberger \& Valente-Moreira (2000) que registraram oito espécies para a lagoa Tarumã, em Ponta Grossa; Tavares \& Valente-Moreira (2000) no estudo da diatomoflórula do lago de Cascavel encontraram oito espécies e uma variedade de Pinnularia; Bittencourt-Oliveira (2002) e Moura

\footnotetext{
1 Universidade Federal do Paraná, Departamento de Botânica, Laboratório de Ficologia, Curitiba, PR, Brasil

2 Autor para correspondência: ptremarin@gmail.com
} 
\& Bittencourt-Oliveira (2004), em duas publicações, uma sobre a flora fitoplanctônica e outra contemplando apenas as diatomáceas do rio Tibagi, em Londrina, registraram cinco espécies de Pinnularia; Ludwig et al. (2005) que encontraram 11 representantes da família para os lagos do Jardim Botânico de Curitiba, sendo duas novas citações para o estado; Brassac \& Ludwig (2006) que realizaram o estudo das Pinnulariaceae dos rios da área de abrangência da usina hidrelétrica de Salto Caxias, registrando 19 táxons infragenéricos, sendo sete novos registros para o estado; e Procopiak et al. (2006) que listaram 16 espécies e uma variedade quando do levantamento das diatomáceas do litoral estado.

O rio Guaraguaçu é um ecossistema litorâneo paranaense, importante pela sua dimensão e volume d'água, e que sofre influência do regime de marés. Ambientes reófilos estuarinos apresentam elevada riqueza de espécies, porém são pouco estudados no Brasil. O objetivo principal deste trabalho foi realizar o levantamento das espécies e variedades taxonômicas das diatomáceas pertencentes à família Pinnulariaceae do rio Guaraguaçu, Paraná.

\section{Material e métodos}

O rio Guaraguaçu está localizado na bacia hidrográfica litorânea paranaense, nos municípios de Pontal do Paraná, Paranaguá e Matinhos, estado do Paraná, sul do Brasil (Fig. 1). Vinte e nove amostras contendo material planctônico e perifítico foram coletadas em seis estações de

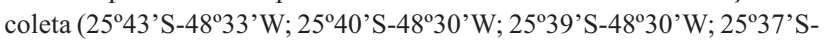
$48^{\circ} 30^{\prime} \mathrm{W}$; $\left.25^{\circ} 36^{\prime} \mathrm{S}-48^{\circ} 29^{\prime} \mathrm{W}, 25^{\circ} 35^{\prime} \mathrm{S}-48^{\circ} 29^{\prime} \mathrm{W}\right)$. A coleta foi realizada nos meses de abril e outubro de 2003 (Tab. 1). As amostras planctônicas foram coletadas com auxílio de rede de plâncton com abertura de malha de $25 \mu \mathrm{m}$ e as de perifíton por meio de raspagem de partes de macrófitas aquáticas submersas. O material foi oxidado segundo a técnica de Simonsen (1974) modificada por Moreira-Filho \& Valente-Moreira (1981). Para a análise do material em microscopia óptica (MO) foram confeccionadas lâminas permanentes com resina Naphrax ${ }^{\circledR}$ (I.R.: 1.74). Ilustrações em MO foram obtidas em fotomicroscópio Olympus BX40 com equipamento de captura de imagem Olympus DP071. As amostras foram registradas no Herbário da Universidade Federal do Paraná (UPCB). Para todos os táxons encontrados foram providenciadas medidas e chaves dicotômicas de identificação taxonômica. Para os táxons com primeiro registro para o estado do Paraná foram feitas descrições, e comentários taxonômicos quando estes apresentaram alguma problemática relevante. As demais espécies encontradas no material foram listadas na Tab. 2. A terminologia empregada seguiu Round et al. (1990), Barber \& Haworth (1981) e Hendey (1964).

Tabela 1. Dados de coleta da pesquisa no período abril e outubro de 2003.

\begin{tabular}{|c|c|c|c|c|c|c|}
\hline UPCB & Estação & Município & Salinidade & Habitat & Data & Coletores \\
\hline 47493 & 2 & Pontal do Paraná & 0 & Plâncton & $16 / \mathrm{IV} / 2003$ & P. Bigunas, T. Ludwig \& A. Campos \\
\hline 47494 & 2 & Pontal do Paraná & 0 & Perifíton & 16/IV/2003 & P. Bigunas, T. Ludwig \& A. Campos \\
\hline 47495 & 3 & Pontal do Paraná & 0 & Plâncton & $16 / \mathrm{IV} / 2003$ & P. Bigunas, T. Ludwig \& A. Campos \\
\hline 47496 & 3 & Pontal do Paraná & 0 & Perifíton & 16/IV/2003 & P. Bigunas, T. Ludwig \& A. Campos \\
\hline 47497 & 4 & Pontal do Paraná & 0 & Plâncton & $16 / \mathrm{IV} / 2003$ & P. Bigunas, T. Ludwig \& A. Campos \\
\hline 47498 & 4 & Pontal do Paraná & 0 & Perifíton & $16 / \mathrm{IV} / 2003$ & P. Bigunas, T. Ludwig \& A. Campos \\
\hline 47499 & 4 & Pontal do Paraná & 2 & Plâncton & 16/IV/2003 & P. Bigunas, T. Ludwig \& A. Campos \\
\hline 47500 & 4 & Pontal do Paraná & 0 & Perifíton & $16 / \mathrm{IV} / 2003$ & P. Bigunas, T. Ludwig \& A. Campos \\
\hline 47501 & 5 & Pontal do Paraná & 10 & Plâncton & $16 / \mathrm{IV} / 2003$ & P. Bigunas, T. Ludwig \& A. Campos \\
\hline 47502 & 5 & Pontal do Paraná & 4 & Plâncton & 16/IV/2003 & P. Bigunas, T. Ludwig \& A. Campos \\
\hline 47503 & 5 & Pontal do Paraná & 4 & Perifíton & 16/IV/2003 & P. Bigunas, T. Ludwig \& A. Campos \\
\hline 47506 & 6 & Pontal do Paraná & 13 & Perifíton & 16/IV/2003 & P. Bigunas, T. Ludwig \& A. Campos \\
\hline 47509 & 1 & Matinhos & 0 & Plâncton & $24 / \mathrm{X} / 2003$ & P. Bigunas, T. Ludwig \& J. Silva \\
\hline 47510 & 1 & Matinhos & 0 & Perifíton & $24 / \mathrm{X} / 2003$ & P. Bigunas, T. Ludwig \& J. Silva \\
\hline 47511 & 1 & Matinhos & 0 & Perifíton & $24 / \mathrm{X} / 2003$ & P. Bigunas, T. Ludwig \& J. Silva \\
\hline 47512 & 2 & Pontal do Paraná & 0 & Plâncton & $24 / \mathrm{X} / 2003$ & P. Bigunas, T. Ludwig \& J. Silva \\
\hline 47513 & 2 & Pontal do Paraná & 0 & Perifíton & $24 / \mathrm{X} / 2003$ & P. Bigunas, T. Ludwig \& J. Silva \\
\hline 47514 & 3 & Pontal do Paraná & 0 & Plâncton & $24 / \mathrm{X} / 2003$ & P. Bigunas, T. Ludwig \& J. Silva \\
\hline 47515 & 3 & Pontal do Paraná & 0 & Perifíton & $24 / \mathrm{X} / 2003$ & P. Bigunas, T. Ludwig \& J. Silva \\
\hline 47516 & 3 & Pontal do Paraná & 0 & Perifíton & $24 / \mathrm{X} / 2003$ & P. Bigunas, T. Ludwig \& J. Silva \\
\hline 47517 & 4 & Pontal do Paraná & 0 & Perifíton & $24 / \mathrm{X} / 2003$ & P. Bigunas, T. Ludwig \& J. Silva \\
\hline 47518 & 4 & Pontal do Paraná & 0 & Perifíton & $24 / \mathrm{X} / 2003$ & P. Bigunas, T. Ludwig \& J. Silva \\
\hline 47519 & 5 & Pontal do Paraná & 0 & Plâncton & $24 / \mathrm{X} / 2003$ & P. Bigunas, T. Ludwig \& J. Silva \\
\hline 47520 & 5 & Pontal do Paraná & 0 & Perifíton & $24 / \mathrm{X} / 2003$ & P. Bigunas, T. Ludwig \& J. Silva \\
\hline 47521 & 6 & Pontal do Paraná & 0 & Plâncton & $24 / \mathrm{X} / 2003$ & P. Bigunas, T. Ludwig \& J. Silva \\
\hline 47523 & 2 & Pontal do Paraná & 1 & Plâncton & $24 / \mathrm{X} / 2003$ & P. Bigunas, T. Ludwig \& J. Silva \\
\hline 47524 & 3 & Pontal do Paraná & 1 & Plâncton & $24 / \mathrm{X} / 2003$ & P. Bigunas, T. Ludwig \& J. Silva \\
\hline 47525 & 4 & Pontal do Paraná & 1 & Plâncton & $24 / \mathrm{X} / 2003$ & P. Bigunas, T. Ludwig \& J. Silva \\
\hline 47526 & 5 & Pontal do Paraná & 14 & Plâncton & $24 / \mathrm{X} / 2003$ & P. Bigunas, T. Ludwig \& J. Silva \\
\hline
\end{tabular}




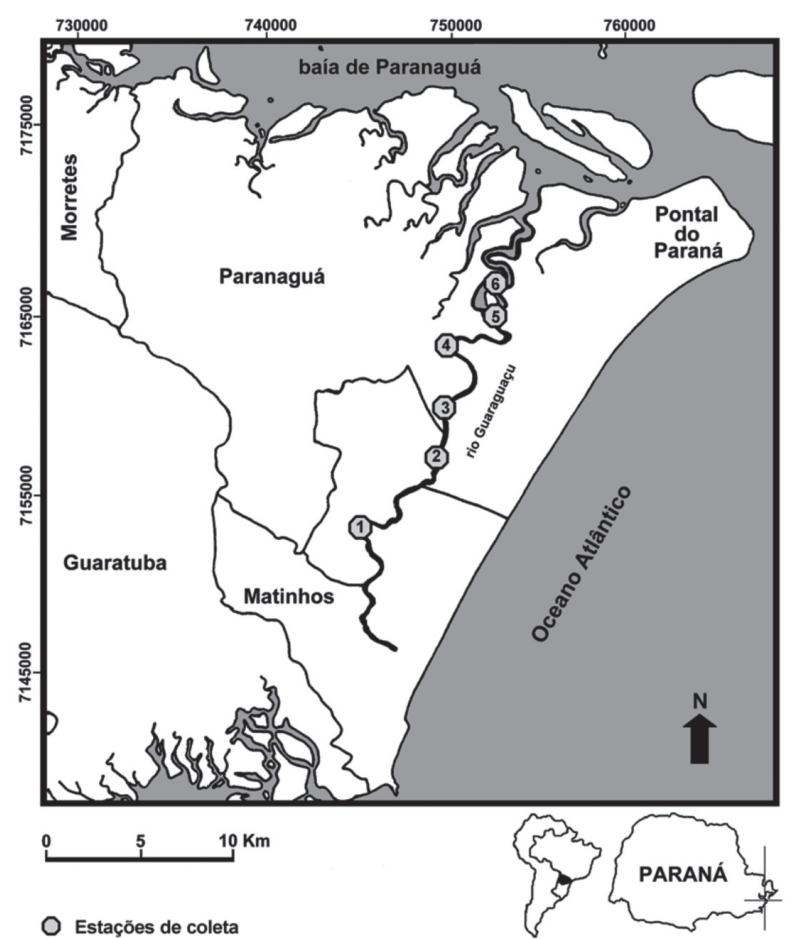

Figura 1. Localização do rio Guaraguaçu no litoral paranaense e estações de amostragem.

\section{Resultados e discussão}

A distinção entre os gêneros Pinnularia Ehrenberg e Caloneis Cleve vem sendo questionada há algum tempo. Tradicionalmente, Caloneis distingue-se de Pinnularia por apresentar estrias mais finamente pontuadas, geralmente paralelas a divergentes nas extremidades e uma ou várias linhas longitunais percorrendo as estrias (Cleve 1894).
Contudo, algumas destas características também podem ser observadas em certas espécies de Pinnularia, especialmente nas de menores dimensões, sugerindo que a delimitação entre estes dois gêneros nem sempre é clara (Mann 2001).

Após o estudo de várias espécies, inclusive do tipo de Caloneis - C. amphisbaena (Bory) Cleve, Round et al. (1990) concluíram que não há características satisfatórias para a separação dos dois gêneros e consideraram os mesmos como sinônimos. Por outro lado, Krammer (2000) comenta que a relação entre os caracteres da valva e o diferente hábito de vida destes gêneros seriam suficientes para sua delimitação. Tanto Pinnularia quanto Caloneis ocorrem em águas continentais e tem poucos representantes marinhos, porém Pinnularia tem preferência por ambientes oligotróficos, com baixo conteúdo eletrolítico e Caloneis ocorre exclusivamente em ambientes mesossapróbios (Krammer 1992; Krammer \& Lange-Bertalot 1986).

Apesar de Caloneis possuir espécies mais finamente estriadas, a estrutura das estrias, o sistema de rafe, a morfologia e ornamentação do cíngulo, a morfologia dos plastídios e dos pirenóides, e a reprodução sexuada são similares aos de Pinnularia, indicando que o gênero Caloneis não apresenta característica morfológica diferencial de Pinnularia que sustente a separação de ambos (Mann 2001).

Mann (2001) comentou que dados de genética molecular poderiam indicar se Caloneis é um grupo monofilético, mas que ainda não há evidências para tal argumentação por haver poucas seqüências genéticas de membros de Pinnulariceae que permitam uma análise mais conclusiva. Um estudo aprofundado das relações existentes entre Pinnularia e Caloneis faz-se necessário ao esclarecimento desta problemática taxonômica.

\section{FAMÍLIA PINNULARIACEAE}

\section{Gênero Caloneis Cleve}

Chave para identificação das espécies de Caloneis:

1. Área central retangular, expandida até as margens da valva

2. Estriação conspícua, 18 a $24 \mathrm{em} 10 \mu \mathrm{m}$.

C. bacillum var. bacillum

2. Estriação inconspícua. C. hyalina var. hyalina

1. Área central arredondada, não expandida até as margens da valva

3. Estrias paralelas a radiadas em direção às extremidades, esterno da rafe lanceolado C. westii var. westii

3. Estrias fortemente radiadas a paralelas em direção às extremidades, esterno da rafe linear. C. formosa var. formosa

Caloneis formosa (Gregory) Cleve var. formosa, Kongl. Svens. Vet. Akad. Handl., 26(2): 57, 1894.

Fig. 2

Valva linear-lanceolada; extremidades atenuadas; esterno da rafe linear, estreito; área central arredondada; rafe filiforme, reta, extremidades proximais fletidas; estrias curvo-radiadas a paralelas nas extremidades. Eixo apical: $94,8 \mu \mathrm{m}$; eixo transapical: $23,7 \mu \mathrm{m} ; 12$ estrias em $10 \mu \mathrm{m}$.

C. permagna (Bailey) Cleve, espécie semelhante à $C$. formosa, difere desta pela forma rombo-lanceolada da valva e pelos maiores valores de eixo transapical, o que acarreta uma relação compr./larg. inferior (em média 3) à das formas linear-lanceoladas de C. formosa (em média 5). Hustedt (1930) registrou 85-220 $\mu \mathrm{m}$ de comprimento e $35-55 \mu \mathrm{m}$ de largura para C. permagna, e 45-133 $\mu \mathrm{m}$ de comprimento e 8-28 $\mu \mathrm{m}$ de largura para $C$. formosa.

Material examinado: Brasil. Paraná: Pontal do Paraná, rio Guaraguaçu, 16/IV/2003, Bigunas et al. (UPCB 47506). 
Gênero Pinnularia Ehrenberg

Chave para identificação das espécies de Pinnularia:

1. Rafe filiforme

2. Esterno da rafe lanceolado

3. Extremidades largamente arredondadas ou atenuado-arredondadas

4. Valvas com eixo apical superior a $67 \mu \mathrm{m}$

P. meridiana var. parallela

4. Valvas com eixo apical inferior a $36,5 \mu \mathrm{m}$

5. Área central ampla, quadrangular

P. oominensis var. oominensis

5. Área central estreita, linear P. dornii var. dornii

3. Extremidades capitadas

6. Valvas linear-lanceoladas; extremidades pouco capitadas

P. brauniana var. brauniana

6. Valvas lineares; extremidades fortemente capitadas

P. rumrichae var. rumrichae

2. Esterno da rafe linear

7. Extremidades truncadas

P. borealis var. rectangularis

7. Extremidades capitadas, subcapitadas a atenuado-arredondadas

8. Estrias convergindo abruptamente em direção às extremidades da valva

P. acoricola var. acoricola

8. Estrias convergindo levemente em direção às extremidades da valva

9. Valvas com eixo transapical superior a $14 \mu \mathrm{m}$

10. Valvas lineares; extremidades capitadas a subcapitadas

P. divergens var. media

10. Valvas linear-lanceoladas; extremidades subcapitadas

P. decrescens var. ignorata

9. Valvas com eixo transapical inferior a $6,2 \mu \mathrm{m}$.

P. subcapitata var. subcapitata

1. Rafe complexa

11. Área central atingindo as margens valvares

12. Margens valvares trionduladas

13. Margens fortemente onduladas

P. divergens var. mesoleptiformis

13. Margens levemente onduladas

14. Extremidades cuneadas

15. Esterno da rafe linear, estreito

Pinnularia sp.1

15. Esterno da rafe amplamente lanceolado

P. hudsonii var. hudsonii

14. Extremidades subcapitadas

16. Esterno da rafe lanceolado; extremidades proximais da rafe fletidas, dilatadas em poro

P. subgibba var. undulata

16. Esterno da rafe linear; extremidades proximais da rafe retas, não dilatadas em poro

P. graciloides var. latecapitata

12. Margens valvares não trionduladas

17. Valvas intumescidas na região mediana

18. Área central rômbica; esterno da rafe pouco expandido

19. Extremidades arredondadas

P. stoermeri var. stoermeri

19. Extremidades largamente arredondadas

20. Valvas com eixo transapical superior a $25 \mu \mathrm{m}$

P. divergens var. malayensis

20. Valvas com eixo transapical igual a $14,7 \mu \mathrm{m}$

P. divergens var. biconstricta

18. Área central linear, ampla; esterno da rafe largamente expandido

21. Eixo apical superior a $147 \mu \mathrm{m}$; valvas fortemente intumescidas

P. hyalina var. hyalina

21. Eixo apical igual a $64,2 \mu \mathrm{m}$; valvas levemente intumescidas

P. subgibba var. subgibba

17. Valvas não intumescidas na região mediana

22. Presença de intumescimento próximo das extremidades valvares

P. rostratissima var. parva

22. Ausência de intumescimento próximo das extremidades valvares

23. Esterno da rafe linear

24. Extremidades capitadas a subcapitadas

25. Valvas com eixo apical superior a $71 \mu \mathrm{m}$

P. divergens var. divergens 
25. Valvas com eixo apical inferior a $44 \mu \mathrm{m}$ de comprimento

P. grunowii var. grunowii

24. Extremidades cuneado-arredondadas a amplamente atenuado-arredondadas

26. Área central rômbica, simétrica, com espessamento silíceo próximo das margens da valva

26. Área central linear, assimétrica, sem espessamento silíceo próximo das margens da valva

P. microstauron var. microstauron

23. Esterno da rafe lanceolado

27. Extremidades cuneado-arredondadas; área central estreita

28. Valvas com eixo apical superior a $86 \mu \mathrm{m}$

P. acuminata var. novaezealandica

28. Valvas com eixo apical inferior a de $67 \mu \mathrm{m}$

P. inconstans var. inconstans

27. Extremidades subcapitadas a amplamente rostrado-arredondadas; área central ampla

29. Valvas lineares; externo da rafe estreito a pouco expandido

P. gibba var. gibba

29. Valvas linear-lanceoladas; externo da rafe amplo

Pinnualria sp. 2

11. Área central não atingindo as margens valvares

30. Esterno da rafe com granulações grosseiras

31. Esterno da rafe amplo

32. Valvas trionduladas; estrias radiadas a convergentes em direção às extremidades

P. michelcostei var. michelcostei

32. Valvas não trionduladas; estrias paralelas a radiadas nas extremidades

33. Extremidades largamente arredondadas; valvas com eixo apical superior a $54 \mu \mathrm{m}$

P. acrosphaeria var. acrosphaeria

33. Extremidades cuneado-arredondadas; valvas com eixo apical inferior a $42 \mu \mathrm{m}$.

P. acrosphaeria var. acrosphaeria f. minor

31. Esterno da rafe estreito

34. Valvas com leve intumescimento mediano; eixo apical em torno de $125 \mu \mathrm{m}$

P. huckiae var. huckiae

34. Valvas sem intumescimento mediano; eixo apical superior a $200 \mu \mathrm{m}$

P. latevittata var. latevittata

30. Esterno da rafe sem granulações grosseiras

35. Nódulo central grosseiro, fortemente refringente, localizado no mesmo lado das extremidades proximais da rafe

36. Valvas fortemente intumescidas na região mediana.

P. nobilis var. regularis

36. Valvas pouco ou não intumescidas na região mediana

37. Razão comprimento-largura $>7,1$; eixo apical superior a $173 \mu \mathrm{m}$

P. neomajor var. neomajor

37. Razão comprimento-largura $<6,5$; valvas com eixo apical inferior a $157,2 \mu \mathrm{m}$

38. Eixo transapical maior do que $21,5 \mu \mathrm{m}$.

P. viridis var. viridis

38. Eixo transapical menor do que $17,8 \mu \mathrm{m}$

P. viridiformis var. viridiformis

35. Nódulo central mais delicado, pouco ou não refringente

39. Valvas fortemente intumescidas na região mediana.

P. tabellaria var. tabellaria

39. Valvas não intumescidas na região mediana

40. Extremidades capitadas a subcapitadas

41. Esterno da rafe amplo, lanceolado.

P. diversarea var. diversarea

41. Esterno da rafe estreito, linear

42. Área central amplamente lanceolada, simétrica

P. maculata var. maculata

42. Área central arredondada, assimétrica

P. rhombarea var. rhombarea

40. Extremidades atenuado-arredondadas a arredondadas

43. Esterno da rafe amplo

44. Área central arredondada; valvas com 14-16 estrias em $10 \mu \mathrm{m}$

P. butantanum var. butantanum

44. Área central indistinta; valvas com 10 estrias em $10 \mu \mathrm{m}$

P. acuminata var. acuminata

43. Esterno da rafe mais estreito

45. Área central arredondada; valvas com eixo transapical superior a $19 \mu \mathrm{m} \mathrm{de}$

45. Área central lanceolada; valvas com eixo transapical inferior a 9,4 $\mu \mathrm{m}$

P. stidolphii var. stidolphii 
Pinnularia acoricola Hustedt var. acoricola in A. Schmidt, Atlas Diatom., pl. 390, fig. 13-16, 1934.

Fig. 3-6

Valvas linear-lanceoladas; extremidades amplamente atenuado-arredondadas; esterno da

rafe linear, estreito; área central rômbica, ampla, lateralmente expandida, atingindo as margens

da valva; rafe filiforme, extremidades proximais fletidas; estrias radiadas a abruptamente

convergentes em direção às extremidades. Eixo apical: 16,6-29,2 $\mu \mathrm{m}$; eixo transapical: 4-4,7 $\mu \mathrm{m}$; $16-18$ estrias em $10 \mu \mathrm{m}$.

Material examinado: Brasil. Paraná: Pontal do Paraná, rio Guaraguaçu, 16/IV/2003, Bigunas et al. (UPCB 47493, 47494, 47496, 47500); 24/X/2003, Bigunas et al. (UPCB 47509, 47510, 47511, 47512, 47513, 47523, 47514, 47515, 47516, 47517, 47518, 47525, 47519, 47520, 47521).

Pinnularia acrosphaeria var. acrosphaeria f. minor (Peragallo \& Héribaud) Cleve, Kongl. Sven., Vet. Akad. Handl., 27: 86, 1895.

Fig. 7

Valvas lanceoladas; extremidades cuneado-arredondadas; esterno da rafe lanceolado; área central indistinta; rafe filiforme, reta, extremidades proximais fletidas; estrias paralelas a pouco radiadas nas extremidades. Eixo apical: 32,5-41,1 $\mu \mathrm{m}$; eixo transapical: 7,1-7,9 $\mu \mathrm{m}$; $12-15$ estrias em $10 \mu \mathrm{m}$.

Os exemplares encontrados apresentaram semelhança aos ilustrados por Metzeltin \& Lange-Bertalot (2007) e por A. Schmidt et al. (1874-1959), diferindo pouco em relação aos registrados por Cleve (1895): eixo apical 35-70 $\mu \mathrm{m}$, eixo transapical 8-10 $\mu \mathrm{m}$ e 13-14 estrias em $10 \mu \mathrm{m}$. A variedade parva Krammer apresenta maiores dimensões (eixo apical 46-69 $\mu \mathrm{m}$, eixo transapical $12-15 \mu \mathrm{m}$ e $10-12$ estrias em 10 $\mu \mathrm{m})($ Krammer 2000).

Material examinado: Brasil. Paraná: Pontal do Paraná, rio Guaraguaçu, 16/IV/2003, Bigunas et al. (UPCB 47497).

Pinnularia acuminata Wm. Smith var. acuminata, Syn. British. Diat., 1: 55, pl. 18, fig. 164, 1853.

Fig. 8

Valva linear-lanceolada; extremidades atenuado-arredondadas; esterno da rafe lanceolado, amplo; área central indistinta; rafe complexa, extremidades proximais fletidas; estrias levemente radiadas a convergentes nas extremidades. Eixo apical: $65,9 \mu \mathrm{m}$; eixo transapical: $12,6 \mu \mathrm{m} ; 10$ estrias em $10 \mu \mathrm{m}$.

A espécie diferencia-se de $P$. pseudoacuminata Metzeltin $\&$ Krammer pela forma das extremidades valvares, ornamentação do esterno da rafe e número de estrias. P. pseudoacuminata apresenta extremidades cuneado-arredondadas, esterno da rafe pouco ornamentado em exemplares maiores e estrias mais grosseiras (7-8 em $10 \mu \mathrm{m})$. Enquanto que $P$. acuminata é descrita como tendo estremidades acuminadas a agudamente arredondadas, esterno da rafe sem ornamentação e 8-10 estrias em $10 \mu \mathrm{m}$ (Krammer 2000).

Material examinado: Brasil. Paraná: Pontal do Paraná, rio Guaraguaçu, 24/X/2003, Bigunas et al. (UPCB 47513).

Pinnularia acuminata var. novaezealandica Krammer, Diat.

Eur., 1: 159, pl. 148, fig. 1-5, 2000.

Fig. 9

Valvas linear-lanceoladas; extremidades cuneado-arredondadas; esterno da rafe amplamente linear-lanceolado; área central linear, sutilmente assimétrica, atingindo as margens valvares; rafe complexa, extremidades proximais fletidas; estrias radiadas a levemente convergentes nas extremidades. Eixo apical: 86,1-133,3 $\mu \mathrm{m}$; eixo transapical: 13,3-14,1 $\mu \mathrm{m} ; 10$ estrias em $10 \mu \mathrm{m}$.

Difere da variedade típica da espécie pelas maiores dimensões valvares (var. acuminata - eixo apical 40-84 $\mu \mathrm{m}$, eixo transapical $12-16 \mu \mathrm{m}$, e var. novaezealandica - eixo apical 70-110 $\mu \mathrm{m}$, eixo transapical 14,7-16,9) e presença de área central assimétrica que se estende até as margens da valva (Metzeltin \& Lange-Bertalot 2007; Krammer 2000).

Material examinado: Brasil. Paraná: Pontal do Paraná, rio Guaraguaçu, 24/X/2003, Bigunas et al. (UPCB 47509).

Pinnularia decrescens var. ignorata Krammer, Diat. Eur., 1: 65, pl. 40, fig. 1-3, 2000.

Fig. 10-12

Valvas linear-lanceoladas; extremidades subcapitadas; esterno da rafe linear, amplo; área central rômbica, atingindo as margens da valva; rafe filiforme, extremidades proximais fletidas; estrias radiadas a convergentes nas extremidades. Eixo apical: 57,8-63,3 $\mu \mathrm{m}$; eixo transapical: 13,9-15 $\mu \mathrm{m}$; 9 estrias em $10 \mu \mathrm{m}$.

Material examinado: Brasil. Paraná: Pontal do Paraná, rio Guaraguaçu, 16/IV/2003, Bigunas et al. (UPCB 47493).

Pinnularia divergens var. malayensis Hustedt, Inter. Rev. Hydrobiol. Hydrogr., 42: 82, fig. 159, 1942.

Fig. 13-15

Valvas lineares, intumescidas na região mediana; extremidades amplamente arredondadas; esterno da rafe linear, amplo; área central rômbica, expandida até as margens da valva; rafe complexa, extremidades proximais sutilmente fletidas; estrias radiadas a convergentes em direção às extremidades. Eixo apical: 115,3-176 $\mu \mathrm{m}$; eixo transapical: 25,3-30,8 $\mu \mathrm{m}$; 7 estrias em $10 \mu \mathrm{m}$.

Material examinado: Brasil. Paraná: Pontal do Paraná, rio Guaraguaçu, 16/IV/2003, Bigunas et al. (UPCB 47496); 24/X/2003, Bigunas et al. (UPCB 47511, 47512, 47514, 47524). 
Pinnularia divergens var. media Krammer, Diat. Eur., 1: 61, pl. 34, fig. 1-5, 10, 2000.

Fig. 16-19

Valvas lineares; extremidades capitadas a subcapitadas; esterno da rafe linear, pouco expandido; área central rômbica, atingindo as margens da valva; rafe filiforme, extremidades proximais quase retas; estrias radiadas a convergentes próximas às extremidades. Eixo apical: $33,1-49,4 \mu \mathrm{m}$; eixo transapical: 8,8-9,4 $\mu \mathrm{m} ; 12-14$ estrias em $10 \mu \mathrm{m}$.

Material examinado: Brasil. Paraná: Pontal do Paraná, rio Guaraguaçu, 16/IV/2003, Bigunas et al. (UPCB 47496); 24/X/2003, Bigunas et al. (UPCB 47511, 47512, 47513, 47523, 47514, 47515, 47516, 47518).

Pinnularia divergens var. mesoleptiformis Krammer \& Metzeltin in Metzeltin \& Lange-Bertalot, Iconogr. Diatomol., 5: 170, pl. 173, fig. 1-4, 1998.

Fig. 20-23

Valvas linear-lanceoladas, com margens trionduladas, ondulação mediana levemente mais pronunciada que as demais; extremidades amplamente capitadas; esterno da rafe linear, pouco expandido; área central rômbica, expandida até as margens da valva; espessamento silicoso marginal presente na região mediana da valva; rafe complexa, extremidades proximais fletidas; estrias radiadas a convergentes em direção às extremidades. Eixo apical: 79,8-83 $\mu \mathrm{m}$; eixo transapical: 11,9-12,6 $\mu \mathrm{m}$; 9-10 estrias em $10 \mu \mathrm{m}$.

Material examinado: Brasil. Paraná: Pontal do Paraná, rio Guaraguaçu, 16/IV/2003, Bigunas et al. (UPCB 47495, 47501).

Pinnularia diversarea Krammer \& Metzeltin var. diversarea in Metzeltin \& Lange-Bertalot, Iconogr. Diatomol., 5: 173, pl. 174, fig. 2-5, 1998.

Fig. 27

Valva linear-lanceolada; extremidades subcapitadas; esterno da rafe amplamente lanceolado; área central arredondada, ampla; rafe complexa, extremidades proximais fletidas; estrias radiadas a levemente convergentes nas extremidades. Eixo apical: 70,3 $\mu \mathrm{m}$; eixo transapical: 15 $\mu \mathrm{m} ; 9$ estrias em $10 \mu \mathrm{m}$.

Material examinado: Brasil. Paraná: Pontal do Paraná, rio Guaraguaçu, 16/IV/2003, Bigunas et al. (UPCB 47494).

Pinnularia dornii Metzeltin var. dornii in Lange-Bertalot \& Metzeltin, Iconogr. Diatomol., 2: 97, pl. 45, fig. 1921, 1996.

Fig. 24-26

Valvas linear-lanceoladas; extremidades atenuadoarredondadas; esterno da rafe lanceolado, amplo; área central linear, lateralmente expandida, atingindo as margens da valva, geralmente assimétrica; rafe filiforme, extremidades proximais fletidas; estrias radiadas a convergentes em direção às extremidades. Eixo apical: 28,4-34 $\mu \mathrm{m}$; eixo transapical: 5,5-6,3 $\mu \mathrm{m} ; 9-12$ estrias em $10 \mu \mathrm{m}$.

Material examinado: Brasil. Paraná: Pontal do Paraná, rio Guaraguaçu, 16/IV/2003, Bigunas et al. (UPCB 47493, 47496, 47498); 24/X/2003, Bigunas et al. (UPCB 47511, 47512, 47513, 47516).

Pinnularia graciloides var. latecapitata Metzeltin \& Krammer in Metzeltin \& Lange-Bertalot, Iconogr. Diatomol., 5: 176, pl. 180, fig. 5-8, 1998.

Fig. 28-31

Valvas linear-lanceoladas, às vezes, levemente trionduladas; extremidades amplamente subcapitadas; esterno da rafe linear, estreito; área central rômbica, atingindo as margens da valva; rafe complexa, extremidades proximais retas; estrias fortemente radiadas a convergentes em direção às extremidades. Eixo apical: 48,2-81,5 $\mu \mathrm{m}$; eixo transapical: 7,9-8,7 $\mu \mathrm{m} ; 10-12$ estrias em $10 \mu \mathrm{m}$.

A var. latecapitata difere da variedade típica por apresentar extremidades mais capitadas e rostradas, margens levemente trionduladas e sutilmente convexas (Metzeltin \& Lange-Bertalot 1998).

Apesar da população estudada ter apresentado alguns indivíduos com variação métrica levemente inferior à registrada para a espécie, as demais características da valva foram coincidentes com as do material tipo.

Material examinado: Brasil. Paraná: Pontal do Paraná, rio Guaraguaçu, 16/IV/2003, Bigunas et al. (UPCB 47496, 47498, 47499, 47501); 24/X/2003, Bigunas et al. (UPCB 47510, 47511, 47512, 47515, 47516, 47521).

Pinnularia hartleyana Greville var. curta Frenguelli, An.

Mus. Nac. Hist. Nat., 37: 397, pl. 2, fig. 8, 1933.

Fig. 32

Valva linear-lanceolada; extremidades cuneado-arredondadas; esterno da rafe linear, pouco expandido; área central rômbica, alcançando as margens da valva; espessamento silíceo marginal, presente na região mediana da valva; rafe complexa, extremidades proximais fletidas; estrias radiadas a convergentes nas extremidades. Eixo apical: $90,8 \mu \mathrm{m}$; eixo transapical: 20,6 $\mu \mathrm{m} ; 8$ estrias em $10 \mu \mathrm{m}$.

O exemplar encontrado apresentou medidas valvares pouco menores às registradas por Frenguelli (1933) quando propos a variedade (111-132 $\mu \mathrm{m}$ de comprimento, 27-29 $\mu \mathrm{m}$ de largura e 6 estrias em $10 \mu \mathrm{m}$ ), contudo as demais características morfológicas da valva concordam com a descrição original.

Material examinado: Brasil. Paraná: Pontal do Paraná, rio Guaraguaçu, 24/X/2003, Bigunas et al. (UPCB 47510).

Pinnularia huckiae Metzeltin \& Lange-Bertalot var. huckiae in Lange-Bertalot, Iconogr. Diatomol., 18: 204, pl. 230, fig. 1-5, 2007.

Fig. 33 

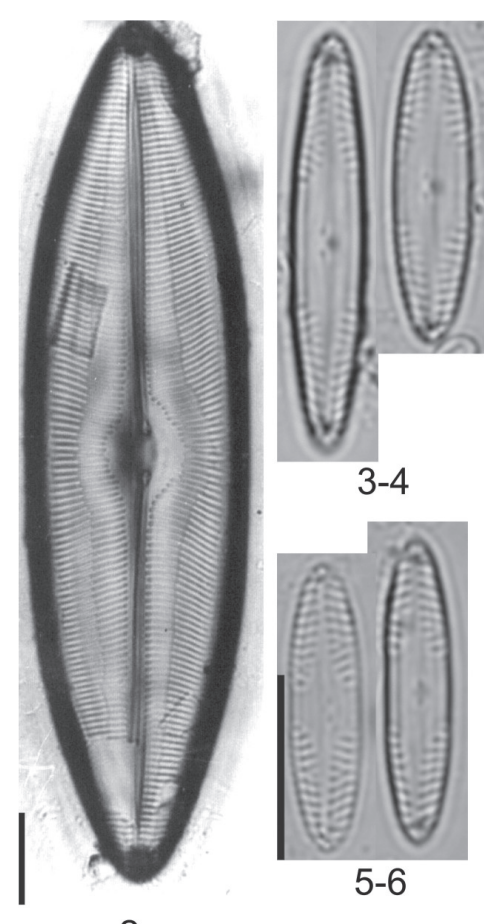

2

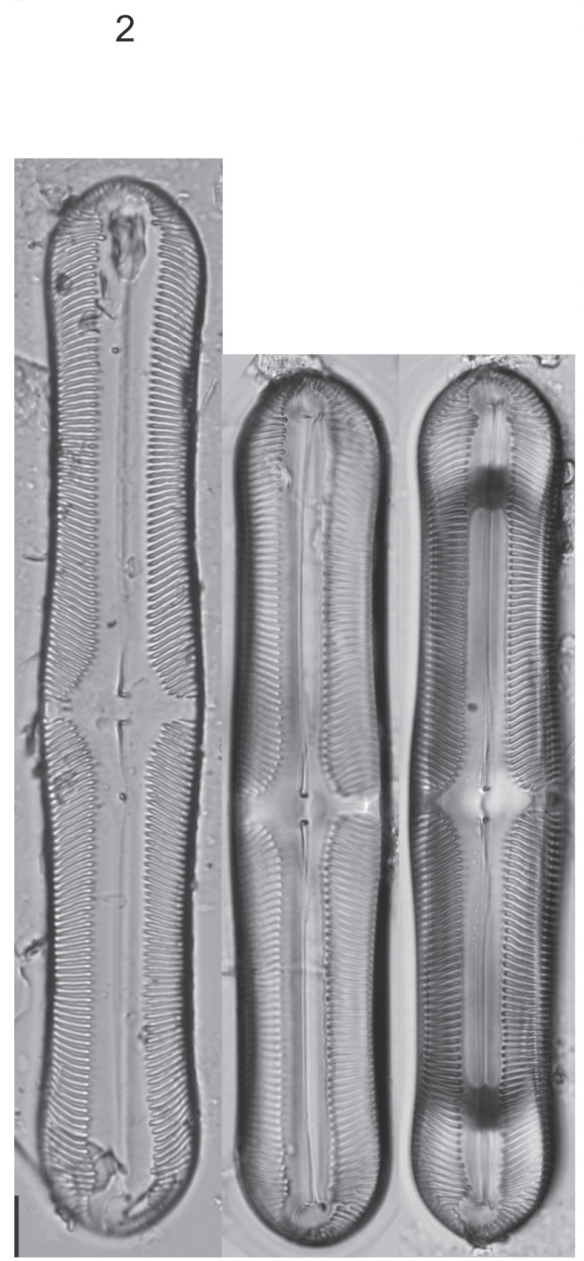

13-15
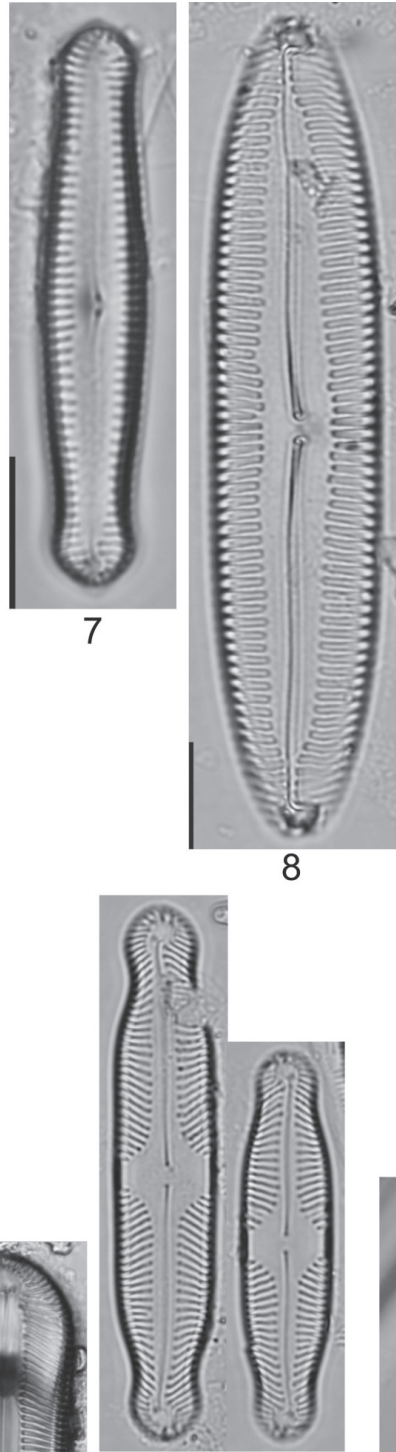

16-17

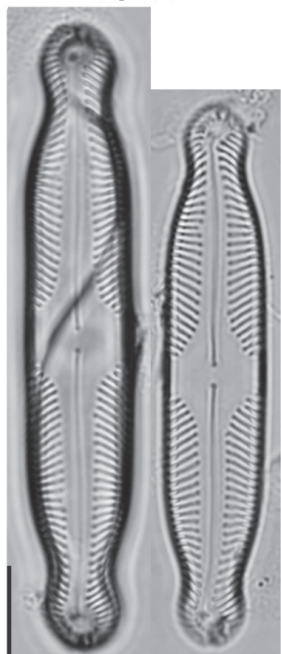

18-19
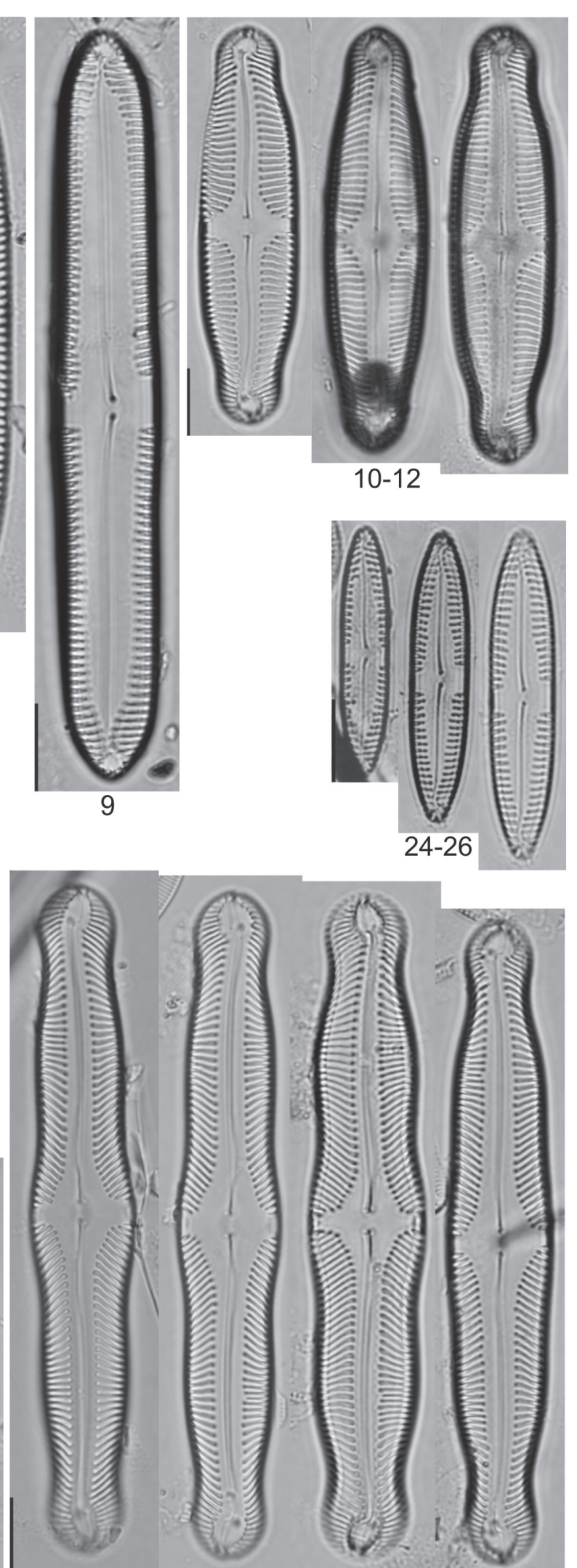

$20-23$

Figuras 2-26. Fig. 2. Caloneis formosa (Gregory) Cleve. Fig. 3-6. Pinnularia acoricola Hustedt. Fig. 7. Pinnularia acrosphaeria f. minor (Peragallo \& Héribaud) Cleve. Fig. 8. Pinnularia acuminata Wm. Smith var. acuminata. Fig. 9. Pinnularia acuminata var. novazealandica Krammer. Fig. 10-12. Pinnularia decrescens var. ignorata Krammer. Fig. 13-15. Pinnularia divergens var. malayensis Hustedt. Fig. 16-19. Pinnularia divergens var. media Krammer. Fig. 20-23. Pinnularia divergens var. mesoleptiformis Krammer \& Metzeltin. Fig. 24-26. Pinnularia dornii Metzeltin. Escalas: $10 \mu \mathrm{m}$. 
Valva lineare com leve intumescimento mediano; extremidades arredondadas; esterno da rafe linear, estreito, ornamentado com pequenos grânulos; área central elíptica não atingindo as margens da valva; rafe complexa, extremidades proximais fletidas; estrias radiadas a convergentes nas extremidades. Eixo apical: 124,8 $\mu \mathrm{m}$; eixo transapical: 20,6 $\mu \mathrm{m}$; 8 estrias em $10 \mu \mathrm{m}$.

Material examinado: Brasil. Paraná: Pontal do Paraná, rio Guaraguaçu, 24/X/2003, Bigunas et al. (UPCB 47514).

Pinnularia hudsonii Metzeltin, Lange-Bertalot \& GacíaRodriguez var. hudsonii in Lange-Bertalot, Iconogr. Diatomol., 15: 156-157, pl. 177, fig. 1-11, 2005.

Fig. 34

Valva lanceolada levemente triondulada; extremidades cuneadas; esterno da rafe lanceolado, amplo; área central expandida até as margens, assimétrica; rafe complexa, extremidades proximais fletidas; estrias encurtadas, radiadas em direção às convergentes nas extremidades. Eixo apical: 89,1 $\mu \mathrm{m}$; eixo transapical: $13,6 \mu \mathrm{m}$; 10 estrias em $10 \mu \mathrm{m}$.

Material examinado: Brasil. Paraná: Pontal do Paraná, rio Guaraguaçu, 24/X/2003, Bigunas et al. (UPCB 47509).

Pinnularia inconstans Mayer var. inconstans, Denkschr. Bayer. Bot. Ges., 13: 46, pl. 5, fig. 15-16 1916.

Fig. 35-40

Valvas linear-lanceoladas; extremidades cuneado-arredondadas; esterno da rafe amplamente linear-lanceolado; área central linear, sutilmente assimétrica, bi ou unilateral; rafe complexa, extremidades proximais fletidas; estrias radiadas a levemente convergentes nas extremidades. Eixo apical: 48,2-66,7 $\mu \mathrm{m}$; eixo transapical: 10,3-11,3 $\mu \mathrm{m}$; 9-11 estrias em $10 \mu \mathrm{m}$.

P. inconstans assemelha-se a P. instabiliformis Krammer \& Lange-Bertalot, contudo a extremidade valvar desta última é mais atenuada (Metzeltin \& Lange-Bertalot 1998). Também se parece com $P$. acuminata var. guyanensis Metzeltin \& Lange-Bertalot e $P$. acuminata var. novaezealandica, porém a estas variedades apresentam menores e maiores dimensões que os exemplares encontrados, respectivamente (var. guyanensis - eixo apical 36-42 $\mu \mathrm{m}$, eixo transapical

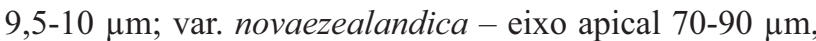
eixo transapical 14,7-16 $\mu \mathrm{m}$ ) (Metzeltin \& Lange-Bertalot 2007; Krammer 2000).

O material analisado concorda com o de Metzeltin \& Lange-Bertalor (2007) e Cleve-Euler (1955).

Material examinado: Brasil. Paraná: Pontal do Paraná, rio Guaraguaçu, 16/IV/2003, Bigunas et al. (UPCB 47497, 47498, 47499, 47500); 24/X/2003, Bigunas et al. (UPCB $47509,47511,47512,47513,47524,47516,47517,47525)$.

Pinnularia latevittata Cleve var. latevittata, Diatomiste, 2(18): 103, 1894.

Fig. 41-44
Valvas lineares; extremidades amplamente arredondadas; esterno da rafe linear, estreito, ornamentado com pequenos grânulos; área central arredondada, não atingindo as margens da valva; rafe complexa, extremidades proximais fletidas; estrias radiadas a levemente convergentes nas extremidades. Eixo apical: 208,7-261,5 $\mu \mathrm{m}$; eixo transapical: 33,9-36,9 $\mu \mathrm{m} ; 5$ estrias em $10 \mu \mathrm{m}$.

Material examinado: Brasil. Paraná: Pontal do Paraná, rio Guaraguaçu, 24/X/2003, Bigunas et al. (UPCB 47509).

Pinnularia meridiana var. parallela Metzeltin \& Krammer in Metzeltin \& Lange-Bertalot, Iconogr. Diatomol., 5: 181, pl. 181, fig. 3, 1998.

Fig. 45

Valva linear; extremidades largamente arredondadas; esterno da rafe lanceolado, amplo; área central amplamente rômbica, alcançando as margens da valva; rafe filiforme, extremidades proximais fletidas; estrias radiadas a convergentes nas extremidades. Eixo apical: 67,2 $\mu \mathrm{m}$; eixo transapical: $11,9 \mu \mathrm{m} ; 10$ estrias em $10 \mu \mathrm{m}$.

A variedade típica da espécie apresenta margens paralelas à levemente convexas e extremidades arredondadas enquanto que a var. parallela possui margens paralelas e extremidades fortemente arredondadas (Metzeltin \& Lange-Bertalot 1998).

Material examinado: Brasil. Paraná: Pontal do Paraná, rio Guaraguaçu, 16/IV/2003, Bigunas et al. (UPCB 47494).

Pinnularia michelcostei Metzeltin \& Lange-Bertalot var. michelcostei in Lange-Bertalot, Iconogr. Diatomol., 18: 208, pl. 257, fig. 4-6, 2007.

Fig. 46

Valva linear, levemente triondulada; extremidades estreitamente arredondadas; esterno da rafe linear, amplo, ornamentado por pequenos grânulos; área central arredondada, não alcançando as margens da valva; rafe complexa, extremidades proximais fletidas; estrias radiadas a convergentes em direção às extremidades. Eixo apical: 118,9 $\mu \mathrm{m}$; eixo transapical: $13,5 \mu \mathrm{m}$; 9 estrias em $10 \mu \mathrm{m}$.

Apesar do exemplar encontrado apresentar medidas valvares pouco maiores daquelas registradas por Metzeltin $\&$ Lange-Bertalot (2007) quando propuseram a espécie (eixo apical 80-96 $\mu \mathrm{m}$, eixo transapical 10-11 $\mu \mathrm{m}$ e 8-9 estrias em $10 \mu \mathrm{m})$, as demais características da valva foram similares. Os autores comentam que $P$. michelcostei apresenta similaridades com $P$. cleveiformis Krammer, porém diferem na forma da rafe, esterno e curvatura das estrias.

Material examinado: Brasil. Paraná: Pontal do Paraná, rio Guaraguaçu, 24/X/2003, Bigunas et al. (UPCB 47512).

Pinnularia nobilis var. regularis Krammer, Diat. Eur., 1: 184, pl. 207, fig. 1-8, pl. 208, fig. 1-7, pl. 209, fig. 1-6. Fig. 47

Valvas lineares, intumescidas na região mediana; extremidades amplamente arredondadas; esterno da rafe linear, 


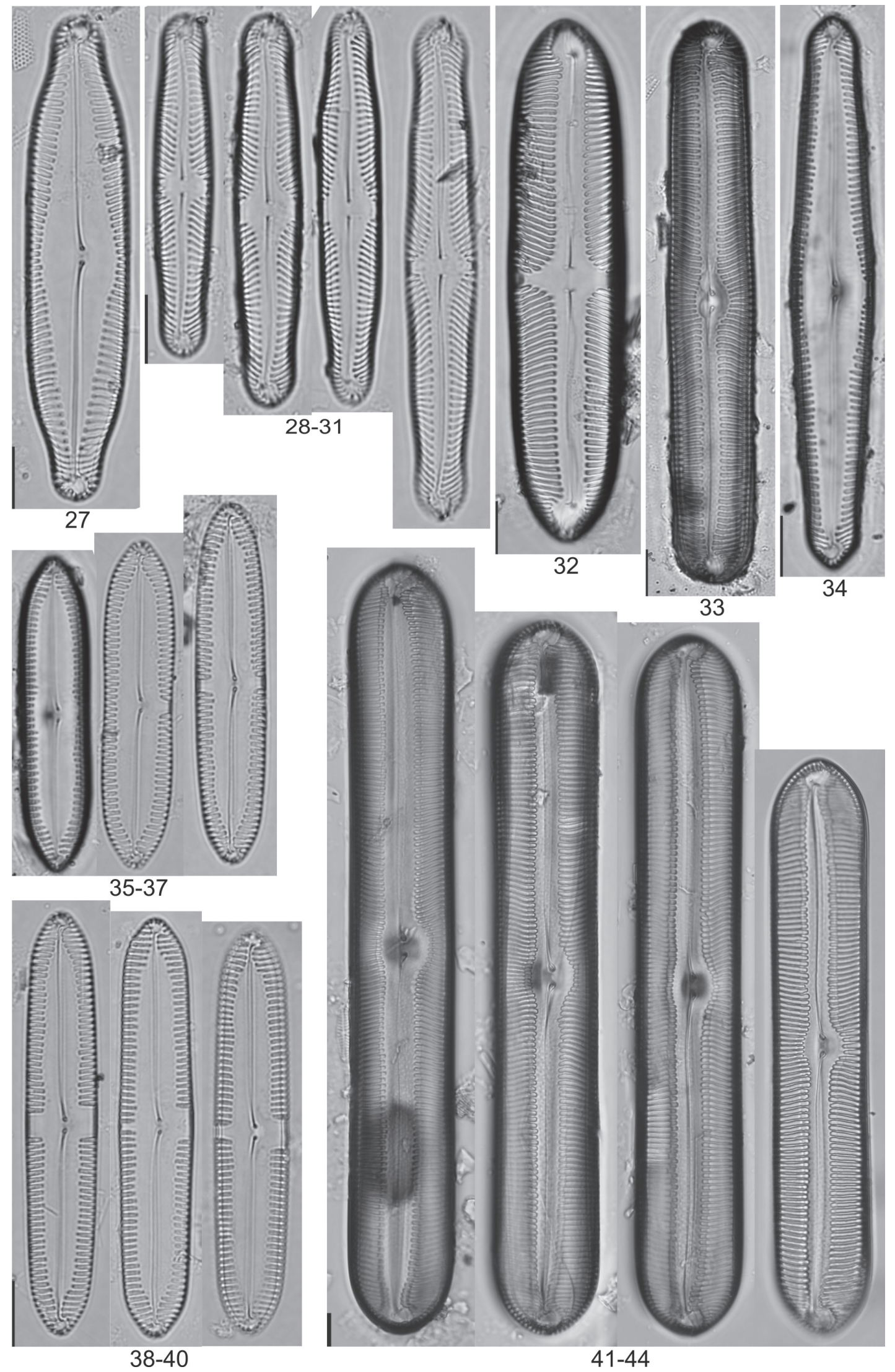

Figuras 27-44. Fig. 27. Pinnularia diversarea Krammer \& Metzeltin. Fig. 28-31. Pinnularia graciloides var. latecapitata Metzeltin \& Krammer. Fig. 32. Pinnularia hartleyana var. curta Frenguelli. Fig. 33 Pinnularia huckiae Metzeltin \& Lange-Bertalot. Fig. 34. Pinnularia hudsonii Metzeltin, Lange-Bertalot \& García-Rodriguez. Fig. 35-40. Pinnularia inconstans Mayer. Fig. 41-44. Pinnularia latevittata Cleve. Escalas: $10 \mu \mathrm{m}$. 
estreito; área central arredondada, mais expandida para um dos lados da valva; rafe complexa, extremidades proximais fletidas; nódulo central refringente, voltado para o mesmo lado das extremidades proximais da rafe; estrias radiadas a convergentes nas extremidades. Eixo apical: 148,9-240 $\mu \mathrm{m}$; eixo transapical: 30,8-37,8 $\mu \mathrm{m}$; 7-10 estrias em $10 \mu \mathrm{m}$.

A variedade regularis difere da típica principalmente pelos limites métricos da valva, sendo que a var. nobilis apresenta 250-350 $\mu \mathrm{m}$ de comprimento e 45-50 $\mu \mathrm{m}$ de largura e a var. regularis tem 176-304 $\mu \mathrm{m}$ de comprimento e 32-40 $\mu \mathrm{m}$ de largura (Krammer 2000).

Material examinado: Brasil. Paraná: Pontal do Paraná, rio Guaraguaçu, 24/X/2003, Bigunas et al. (UPCB 47512).

Pinnularia oominensis Kobayasi var. oominensis in Yamagishi \& Kobayasi, Coll. Agric. Veter. Méd., 7: 37; pl. 9, fig. 75, 76, 1971.

Fig. $48-55$

Valvas lanceoladas; extremidades atenuado-arredondadas; esterno da rafe lanceolado, amplo; área central ampla, quadrangular, atingindo as margens da valva; rafe filiforme, extremidades proximais fletidas para o mesmo lado; estrias encurtadas, sutilmente radiadas a convergentes em direção às extremidades. Eixo apical: 13,4-36,3 $\mu \mathrm{m}$; eixo transapical: 4-6,3 $\mu \mathrm{m} ; 10-16$ estrias em $10 \mu \mathrm{m}$.

Metzeltin \& Lange-Bertalot (1998) comentaram sobre a semelhança desta espécie com $P$. nobilefasciata Krammer \& Metzeltin em relação à variação métrica valvar, densidade de estrias e presença de área central ampla, alcançando as margens da valva. No entanto, quando comparada com $P$. oominensis, $P$. nobilefasciata apresenta esterno da rafe mais linear e estreito, estrias quase paralelas próximo da área central.

Material examinado: Brasil. Paraná: Pontal do Paraná, rio Guaraguaçu, 16/IV/2003, Bigunas et al. (UPCB 47493, 47494, 47495, 47496, 47498, 47499, 47500, 47501); 24/X/2003, Bigunas et al. (UPCB 47509, 47511, 47512, 47513, 47523, 47518, 47520).

Pinnularia rhombarea Krammer var. rhombarea in Metzeltin \& Lange-Bertalot, Iconogr. Diatomol., 5: 185, pl. 175, fig. 1-5, 1998.

Fig. 56

Valva linear-lanceolada; extremidades amplamente subcapitadas; esterno da rafe linear, estreito; área central arredondada, mais expandida para um dos lados da valva; rafe complexa; extremidades proximais fletidas; estrias radiadas a convergentes em direção às extremidades. Eixo apical: $64,7 \mu \mathrm{m}$; eixo transapical: $11,2 \mu \mathrm{m}$; 11 estrias em $10 \mu \mathrm{m}$.

Metzeltin \& Lange-Bertalot (2007) propuseram $P$. wydrzyckae, espécie similar à Pinnularia rhombarea. Os autores comentaram que as duas espécies são facilmente distinguíveis pelo fato de $P$. wydrzyckae ser maior e mais larga (eixo apical 116-126 $\mu \mathrm{m}$, eixo transapical 16-17 $\mu \mathrm{m}$ ).
Material examinado: Brasil. Paraná: Pontal do Paraná, rio Guaraguaçu, 24/X/2003, Bigunas et al. (UPCB 47515).

Pinnularia rostratissima var. parva Metzeltin \& Krammer in Metzeltin \& Lange-Bertalot, Iconogr. Diatomol., 5: 186, pl. 169, fig. 6-9, pl. 203, fig. 3, 6, 1998.

Fig. 57

Valva lanceolada, levemente intumescida próxima às extremidades; extremidades capitadas; esterno da rafe amplamente lanceolado; área central lateralmente expandida, alcançando as margens da valva; rafe filiforme, extremidades proximais fletidas; estrias radiadas a convergentes nas extremidades. Eixo apical: $63,9 \mu \mathrm{m}$; eixo transapical: 9,8 $\mu \mathrm{m} ; 10$ estrias em $10 \mu \mathrm{m}$.

Material examinado: Brasil. Paraná: Pontal do Paraná, rio Guaraguaçu, 24/X/2003, Bigunas et al. (UPCB 47513).

Pinnularia rumrichae Krammer var. rumrichae, Diat. Eur., 1: 110, pl. 84, fig. 13-15, 2000.

Fig. 58-61

Valvas lineares; extremidades capitadas; esterno da rafe lanceolado, amplo; área central expandida até as margens da valva; rafe filiforme, extremidades proximais fletidas; estrias radiadas a convergentes nas extremidades. Eixo apical: 37,9-69,5 $\mu \mathrm{m}$; eixo transapical: 7,4-10,5 $\mu \mathrm{m}$; 9-10 estrias em $10 \mu \mathrm{m}$.

Material examinado: Brasil. Paraná: Pontal do Paraná, rio Guaraguaçu, 16/IV/2003, Bigunas et al. (UPCB 47498, 47499); 24/X/2003, Bigunas et al. (UPCB 47513, 47525).

Pinnularia stidolphii Krammer var. stidolphii, Diat. Eur., 1: 154, pl. 134, fig. 1-7, pl. 183, fig. 3, 2000.

Fig. 62-63

Valvas lineares; extremidades arredondadas; esterno da rafe linear, pouco expandido; área central arredondada; rafe complexa, extremidades proximais fletidas; estrias radiadas a convergentes em direção às extremidades. Eixo apical: 135-136,7 $\mu \mathrm{m}$; eixo transapical: 19,2-20 $\mu \mathrm{m}$; 7-8 estrias em $10 \mu \mathrm{m}$.

Material examinado: Brasil. Paraná: Pontal do Paraná, rio Guaraguaçu, 24/X/2003, Bigunas et al. (UPCB 47509).

Pinnularia stoermeri Metzeltin \& Lange-Bertalot var. stoermeri, Iconogr. Diatomol., 18: 224, pl. 241, fig. 1-3, 2007. Fig. 64

Valva linear intumescida na região mediana; extremidades arredondadas; esterno da rafe linear, amplo; área central rômbica, atingindo as margens da valva; rafe complexa, extremidades proximais fletidas; estrias radiadas a fortemente convergentes em direção às extremidades. Eixo apical: 138,9 $\mu \mathrm{m}$; eixo transapical: $21 \mu \mathrm{m}$; 9 estrias em $10 \mu \mathrm{m}$.

Material examinado: Brasil. Paraná: Pontal do Paraná, rio Guaraguaçu, 24/X/2003, Bigunas et al. (UPCB 47509). 
Pinnularia subgibba Krammer var. subgibba, Biblioth. Diatomol., 26: 126, pl. 3, fig. 3, pl. 26, fig. 1-7, 1992.

Fig. 65

Valva linear, levemente intumescida na região mediana; extremidades largamente arredondadas; esterno da rafe linear, amplo; área central amplamente expandida, atingindo as margens da valva; rafe complexa, extremidades proximais fletidas; estrias radiadas a convergentes em direção às extremidades. Eixo apical: 64,2 $\mu \mathrm{m}$; eixo transapical: 8,4 $\mu \mathrm{m}$; 5 estrias em $10 \mu \mathrm{m}$.

Material examinado: Brasil. Paraná: Pontal do Paraná, rio Guaraguaçu, 16/IV/2003, Bigunas et al. (UPCB 47494).

Pinnularia subgibba var. undulata Krammer, Biblioth. Diatomol., 26: 127, pl. 46, fig. 5, pl. 47, fig.5, 1992. Fig. 66

Valva linear-lanceolada, sutilmente triondulada; extremidades subcapitadas; esterno da rafe lanceolado; área central rômbica alcançando as margens da valva; rafe complexa, extremidades proximais fletidas; estrias radiadas a convergentes nas extremidades. Eixo apical: 53-80 $\mu \mathrm{m}$; eixo transapical: 8,5-10 $\mu \mathrm{m}$; 9-10 estrias em $10 \mu \mathrm{m}$.

Difere da variedade típica da epécie pela margem ondulada, área central mais ampla e menores dimensões valvares (eixo apical 52-84 $\mu \mathrm{m}$, eixo transapical 8-10 $\mu \mathrm{m}$ e 9-10 estrias em $10 \mu \mathrm{m})$ (Krammer 2000).

Material examinado: Brasil. Paraná: Pontal do Paraná, rio Guaraguaçu, 24/X/2003, Bigunas et al. (UPCB 47514).

Pinnularia sudetica (Hilse) Hilse var. sudetica in Rabenhorst, Alg. Eur., n. 1023, 1861.

Fig. 67

Valva linear-lanceolada; extremidades largamente atenuado-arredondadas; esterno da rafe lanceolado, pouco expandido; área central lanceolada; rafe complexa, extremidades proximais fletidas; estrias radiadas a convergentes em direção às extremidades. Eixo apical: $100 \mu \mathrm{m}$; eixo transapical: 9,4 $\mu \mathrm{m} ; 13$ estrias em $10 \mu \mathrm{m}$.

Material examinado: Brasil. Paraná: Pontal do Paraná, rio Guaraguaçu, 16/IV/2003, Bigunas et al. (UPCB 47496).

Pinnularia viridiformis var. Krammer viridiformis, Diat. Eur., 1: 168, pl. 138, fig. 1-9, 2000.

Fig. 68

Valvas linear-lanceoladas; extremidades arredondadas; esterno da rafe linear-lanceolado, pouco expandido; área central arredondada; rafe complexa, extremidades proximais fletidas; estrias levemente radiadas a convergentes nas extremidades. Eixo apical: 93,3-106,4 $\mu \mathrm{m}$; eixo transapical: 17,1-17,8 $\mu \mathrm{m} ; 9$ estrias em $10 \mu \mathrm{m}$.

Apesar da semelhança, $P$. viridis apresenta valvas maiores (eixo apical 100-182 $\mu \mathrm{m}$, eixo transapical 21-30 $\mu \mathrm{m}$ ) que $P$. viridiformis (eixo apical 67-145 $\mu \mathrm{m}$, eixo transapical 14-
$21 \mu \mathrm{m})$. Diferenças métricas também são constatas com var. minor, que como o nome mesmo diz compreende indivíduos menores, com 46-112 $\mu \mathrm{m}$ de comprimento e 12,7-15,1 $\mu \mathrm{m}$ de largura (Krammer 2000).

Material examinado: Brasil. Paraná: Pontal do Paraná, rio Guaraguaçu, 24/X/2003, Bigunas et al. (UPCB 47509, 47512).

\section{Pinnularia sp.1}

Fig. 69

Valva linear-lanceolada, sutilmente triondulada; extremidades cuneadas; esterno da rafe linear, pouco expandido; área central rômbica expandindo-se até a margem valvar; rafe complexa, extremidades proximais fletidas; estrias radiadas a convergentes nas extremidades. Eixo apical: 92,2 $\mu \mathrm{m}$; eixo transapical: 12,2 $\mu \mathrm{m} ; 8$ estrias em $10 \mu \mathrm{m}$.

Apenas um exemplar da espécie foi encontrado e este não foi similar a qualquer outra espécie registrada na literatura consultada. Pouca semelhança pode ser constatada com $P$. amazonica Metzeltin \& Lange-Bertalot, porém esta última possui extremidades mais largas, área central mais ampla e maior densidade de estrias (10-11 em $10 \mu \mathrm{m})$. Também, $P$. subgibba var. angustarea Metzeltin \& Lange-Bertalot apresentou certa semelhança, mas as duas espécies diferenciamse principalmente pela curvatura das estrias e tamanho da área central (Metzeltin \& Lange-Bertalot 1998).

Material examinado: Brasil. Paraná: Pontal do Paraná, rio Guaraguaçu, 24/X/2003, Bigunas et al. (UPCB 47514).

\section{Pinnularia sp.2}

Fig. 70-72

Valvas linear-lanceoladas; extremidades subcapitadas; esterno da rafe lanceolado, amplo; área central expandida até as margens da valva; rafe complexa, extremidades proximais fletidas; estrias radiadas a convergentes nas extremidades. Eixo apical: 60-68,2 $\mu \mathrm{m}$; eixo transapical: 9,1-10 $\mu \mathrm{m}$; 8-9 estrias em $10 \mu \mathrm{m}$.

Os exemplares encontrados são semelhantes aos registrados por Metzeltin et al. (2005) para o rio de la Plata, no Uruguai (pl. 170, fig. 1-8). Os autores não denominaram a espécie na obra, o que impossibilitou a determinação específica do material aqui estudado. Semelhanças entre Pinnularia sp. 2 também foram constatadas com $P$. certa Krammer \& Metzeltin, porém esta última apresenta valvas menores (43$54 \mu \mathrm{m}$ de comprimento e 8,4-9,4 $\mu \mathrm{m}$ de largura) e esterno da rafe mais estreito (Metzeltin \& Lange-Bertalot 1998).

Material examinado: Brasil. Paraná: Pontal do Paraná, rio Guaraguaçu, 24/X/2003, Bigunas et al. (UPCB 47509, 47513, 47514).

C. hyalina foi a espécie com melhor distribuição espacial e temporal, pois esteve presente em $96,5 \%$ das amostras analisadas, seguida de $P$. acoricola $(65,5 \%)$ e $P$. acrosphaeria (58,6\%). Maior número de espécies de Pinnulariaceae foram registradas nas estações de amostragem com menor teor de 
Tabela 2. Variação métrica das demais espécies e variedades de Pinnulariaceae encontradas e sua ocorrência nas amostras.

\begin{tabular}{|c|c|c|c|c|c|}
\hline Espécie & Figura & $\begin{array}{l}\text { Eixo apical } \\
\quad(\mu \mathrm{m})\end{array}$ & $\begin{array}{l}\text { Eixo transapical } \\
\qquad(\mu \mathrm{m})\end{array}$ & $\begin{array}{l}\text { Estrias } \\
(10 \mu \mathrm{m})\end{array}$ & Material examinado (UPCB) \\
\hline Caloneis bacillum (Grunow) Cleve var. bacillum & 73 & $16,6-50,6$ & $4-7,9$ & $18-24$ & $\begin{array}{l}47493,47494,47496,47498,47499, \\
47501,47502,47503,47523,47514, \\
47515,47524,47518,47525,47520\end{array}$ \\
\hline Caloneis hyalina Hustedt var. hyalina & $74-76$ & $11,1-24,5$ & $3,2-4,7$ & inconspícuas & $\begin{array}{l}\text { 47493, 47494, 47495, 47496, 47497, } \\
47498,47499,47500,47501,47502, \\
47506,47509,47510,47511,47512, \\
47513,47523,47514,47515,47524, \\
47516,47517,47518,47525,47519, \\
47520,47526,47521\end{array}$ \\
\hline Caloneis westii (Wm. Smith) Hendey var. westii & 77 & $57,8-86,5$ & $18,4-19,2$ & $14-16$ & 47509 \\
\hline $\begin{array}{l}\text { Pinnularia acrosphaeria W. Smith var. } \\
\text { acrosphaeria }\end{array}$ & $78-83$ & $54-89,3$ & $9,1-13,4$ & $11-13$ & $\begin{array}{l}47493,47494,47495,47496,47497 \\
47498,47500,47503,47510,47511 \\
47512,47513,47523,47514,47516, \\
47517,47525\end{array}$ \\
\hline Pinnularia borealis var. rectangularis Carlson & $84-85$ & $21,8-41,1$ & $5,3-7,1$ & $4-6$ & 47514 \\
\hline $\begin{array}{l}\text { Pinnularia brauniana (Grunow) Mills var. } \\
\text { brauniana }\end{array}$ & $86-89$ & $35,5-47,5$ & $6,3-7,8$ & $10-12$ & $47498,47499,47513,47514,47525$ \\
\hline $\begin{array}{l}\text { Pinnularia butantanum (Krasske) Metzeltin var. } \\
\text { butantanum }\end{array}$ & $90-93$ & $65,6-105,9$ & $11,9-13,5$ & $14-16$ & $\begin{array}{l}47493,47496,47497,47498,47500, \\
47501,47509,47510,47511,47513, \\
47523,47524,47516,47517,47525\end{array}$ \\
\hline $\begin{array}{l}\text { Pinnularia divergens var. biconstricta } \\
\text { (Cleve-Euler) Cleve-Euler }\end{array}$ & 94 & 96,7 & 14,7 & 13 & 47511 \\
\hline Pinnularia divergens $\mathrm{Wm}$. Smith var. divergens & $95-96$ & $71,1-120,1$ & $10,9-21,3$ & $9-12$ & $\begin{array}{l}\text { 47494, 47495, 47496, 47497, 47498, } \\
47499,47501,47506,47509,47510 \\
47511,47512,47513,47514,47517 \\
47525\end{array}$ \\
\hline Pinnularia gibba Ehrenberg var. gibba & $97-100$ & $42,7-61,3$ & $8,7-11,5$ & $9-10$ & $\begin{array}{l}47494,47496,47497,47499,47500, \\
47509,47511,47512,47523,47514, \\
47515,47524,47516,47517,47518\end{array}$ \\
\hline Pinnularia grunowii Krammer var. grunowii & $101-102$ & $26,1-43,2$ & $6,3-8,1$ & $12-14$ & $\begin{array}{l}47493,47494,47495,47496,47500 \\
47501,47509,47511,47512,47523 \\
47515,47524,47516,47517,47518 \\
47519\end{array}$ \\
\hline Pinnularia hyalina Hustedt var. hyalina & 103 & $147,8-163,2$ & $21,1-22,2$ & 9 & $\begin{array}{l}47498,47499,47513,47514,47525 \\
47509,47516\end{array}$ \\
\hline $\begin{array}{l}\text { Pinnularia maculata Krammer \& Metzeltin var. } \\
\text { maculata }\end{array}$ & 104 & 75 & 12,1 & 10 & 47515 \\
\hline $\begin{array}{l}\text { Pinnularia microstauron (Ehrenberg) Cleve var. } \\
\text { microstauron }\end{array}$ & 105 & 49,4 & 11,3 & 14 & 47513 \\
\hline Pinnularia neomajor Krammer var. neomajor & $106-107$ & $173,8-242,8$ & $24,5-37,1$ & $6-8$ & $47495,47509,47510$ \\
\hline Pinnularia subcapitata Gregory var. subcapitata & $108-119$ & $31,5-46,2$ & $5,8-6,2$ & $11-14$ & $\begin{array}{l}47493,47494,47496,47497,47511, \\
47512,47513,47524,47517,47518, \\
47525,47521\end{array}$ \\
\hline Pinnularia tabellaria Ehrenberg var. tabellaria & 120 & 113 & 12,6 & 15 & 47496 \\
\hline Pinnularia viridis (Nitzsch) Ehrenberg var. viridis & $121-122$ & $139,2-157,2$ & $21,5-25,3$ & $8-11$ & $\begin{array}{lllll}47494, & 47495, & 47509, & 47510, & 47511, \\
47512, & 47513, & 47514, & 47515, & 47516, \\
47525 & & & & \end{array}$ \\
\hline
\end{tabular}




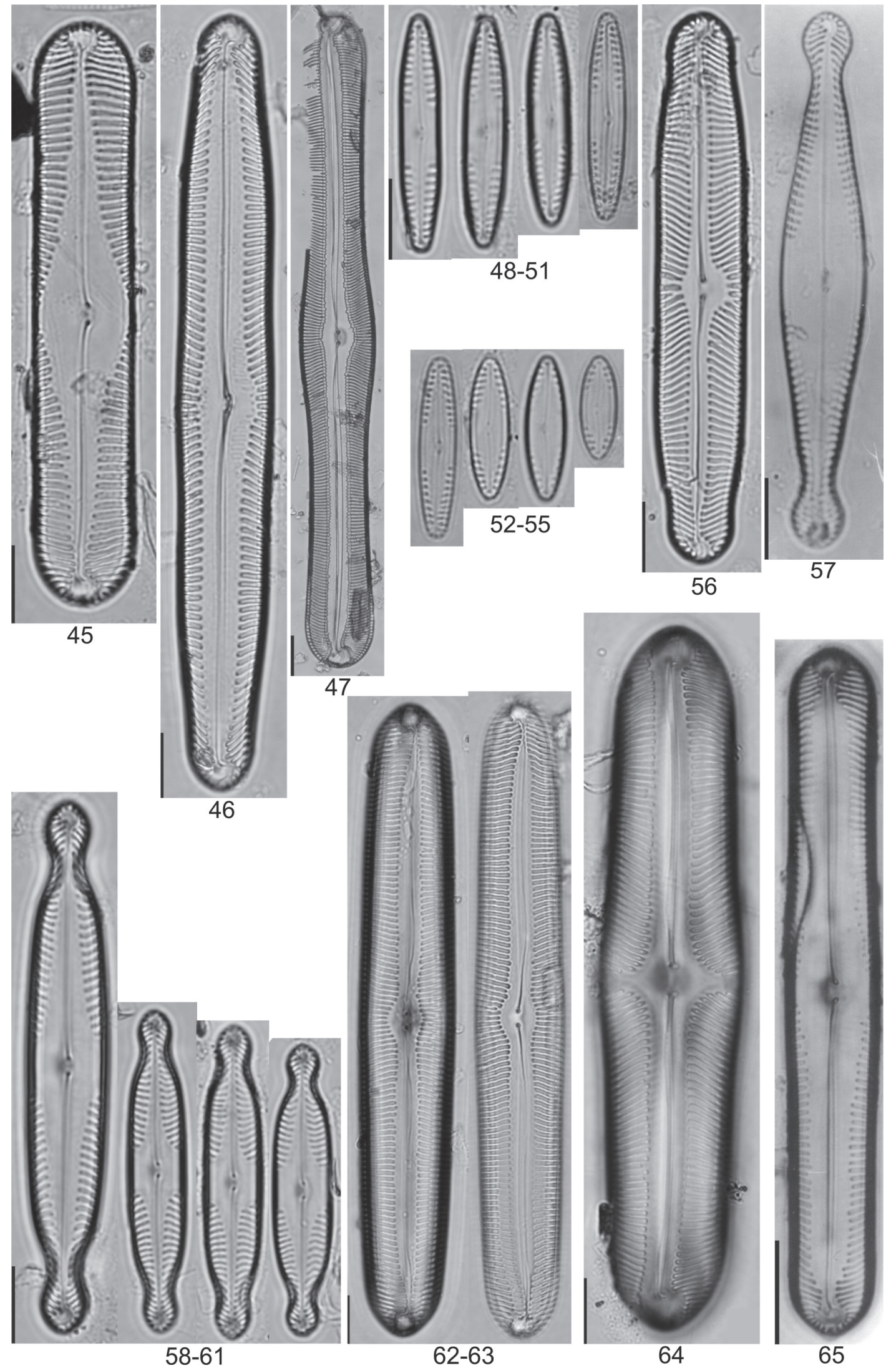

Figuras 45-65. Fig. 45. Pinnularia meridiana var. parallela Metzeltin \& Krammer. Fig. 46. Pinnularia michelcostei Metzeltin \& Lange-Bertalot. Fig. 47. Pinnularia nobilis var. regularis Krammer. Fig. 48-55. Pinnularia oominensis Kobayashi. Fig. 56. Pinnularia rhombarea Krammer. Fig. 57. Pinnularia rostratissima var. parva Metzeltin \& Krammer. Fig. 58-61. Pinnularia rumrichae Krammer. Fig. 62-63. Pinnularia. stidolphii Krammer. Fig. 64. Pinnularia stoermeri Metzeltin \& LangeBertalot. Fig. 65. Pinnularia subgibba Krammer var. subgibba. Escalas: $10 \mu \mathrm{m}$. 


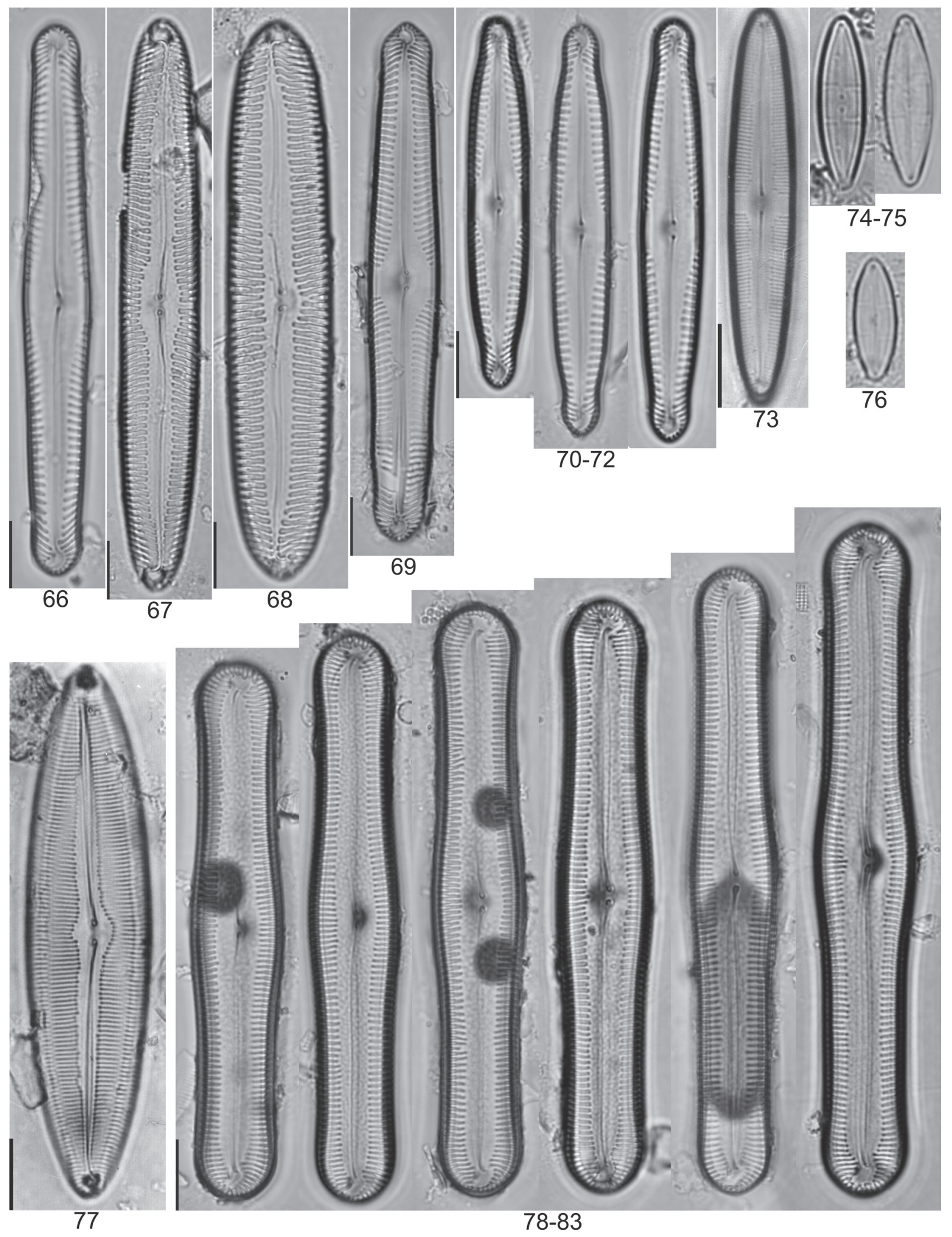

Figuras 66-83. Fig. 66. Pinnularia subgibba var. undulata Krammer. Fig. 67. Pinnularia sudetica (Hilse) Hilse. Fig. 68. Pinnularia viridiformis Krammer. Fig. 69 Pinnularia sp.1. Fig. 70-72. Pinnularia sp.2. Fig. 73. Caloneis bacillum (Grunow) Cleve. Fig. 74-76. Caloneis hyalina Hustedt. Fig. 77. Caloneis westii (Wm. Smith) Hendey. Fig. 78-83. Pinnularia acrosphaeria Wm. Smith var. acrosphaeria. Escalas: $10 \mu \mathrm{m}$. 


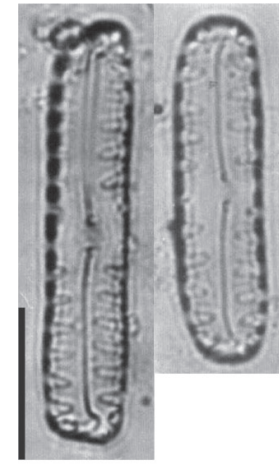

84-85
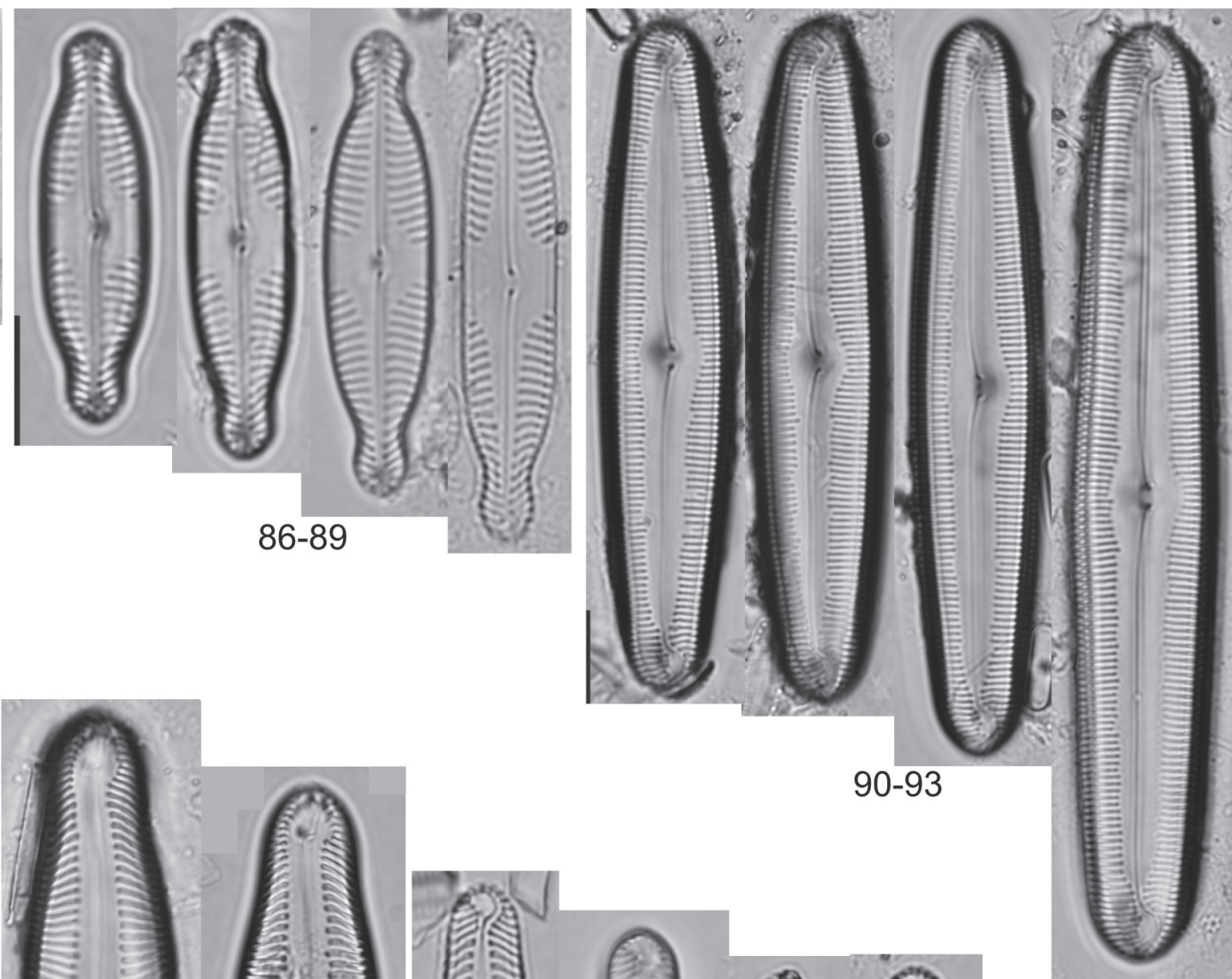

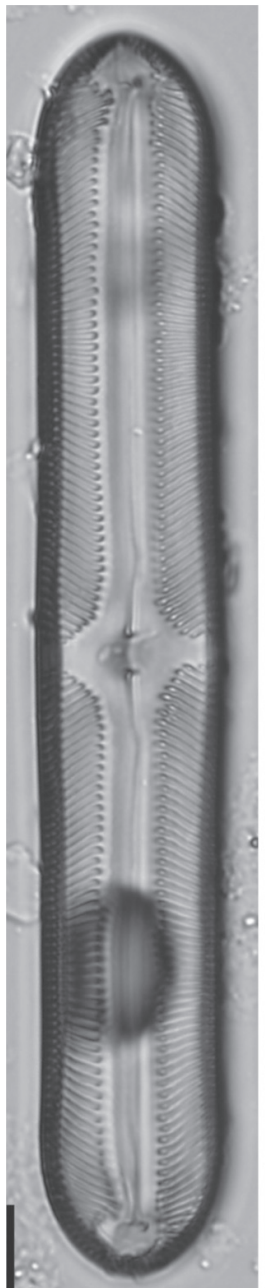

94

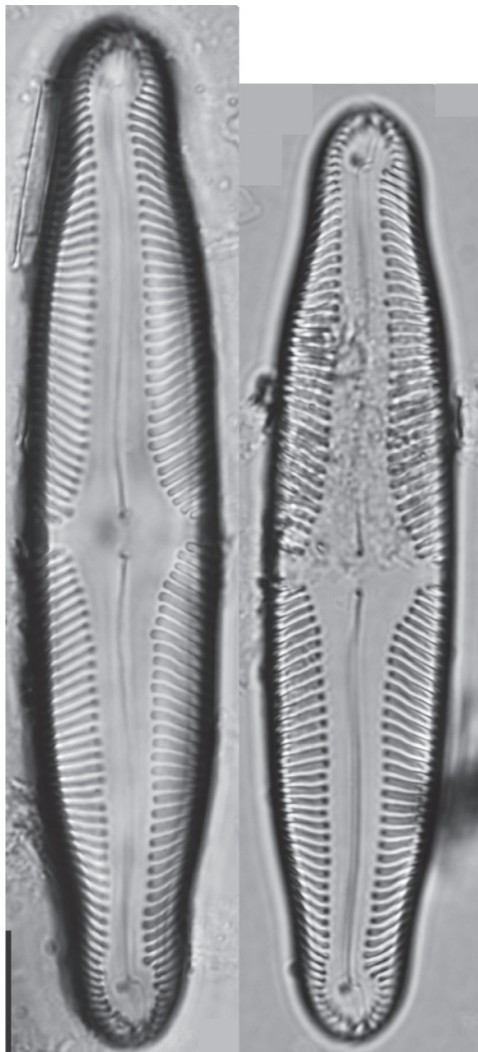

95-96

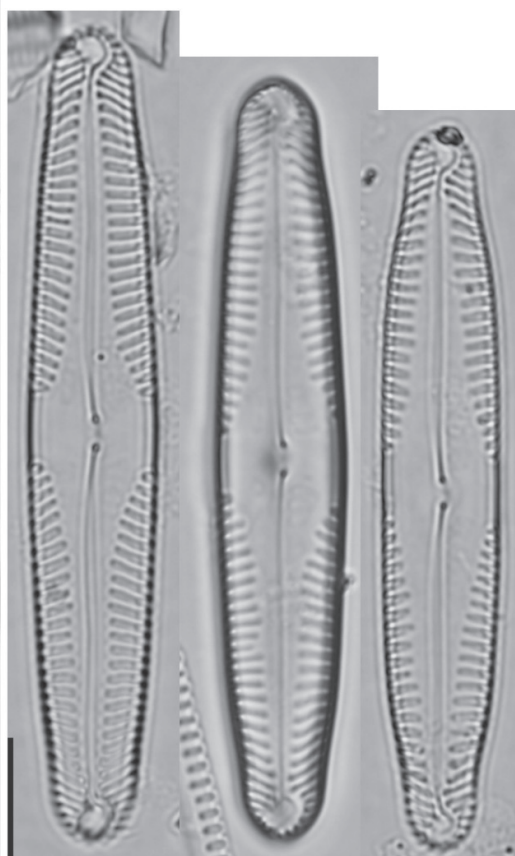

97-100

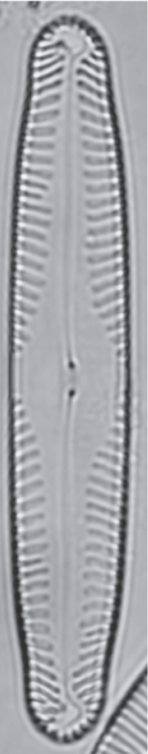

9.

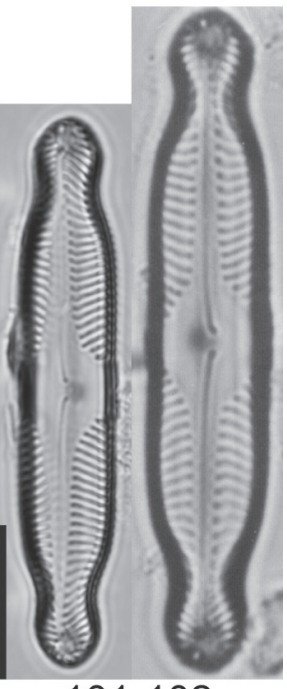

101-102

Figuras 84-102. Fig. 84-85. Pinnularia borealis var. rectangularis Carlson. Fig. 86-89. Pinnularia brauniana (Grunow) Mills. Fig. 90-93. Pinnularia butantanum (Krasske) Metzeltin. Fig. 94. Pinnularia divergens var. biconstricta (Cleve-Euler) Cleve-Euler. Fig. 95-96. Pinnularia divergens Wm. Smith var. divergens. Fig. 97-100. Pinnularia gibba Ehrenberg. Fig. 101-102. Pinnularia grunowii Krammer. Escalas: $10 \mu \mathrm{m}$. 

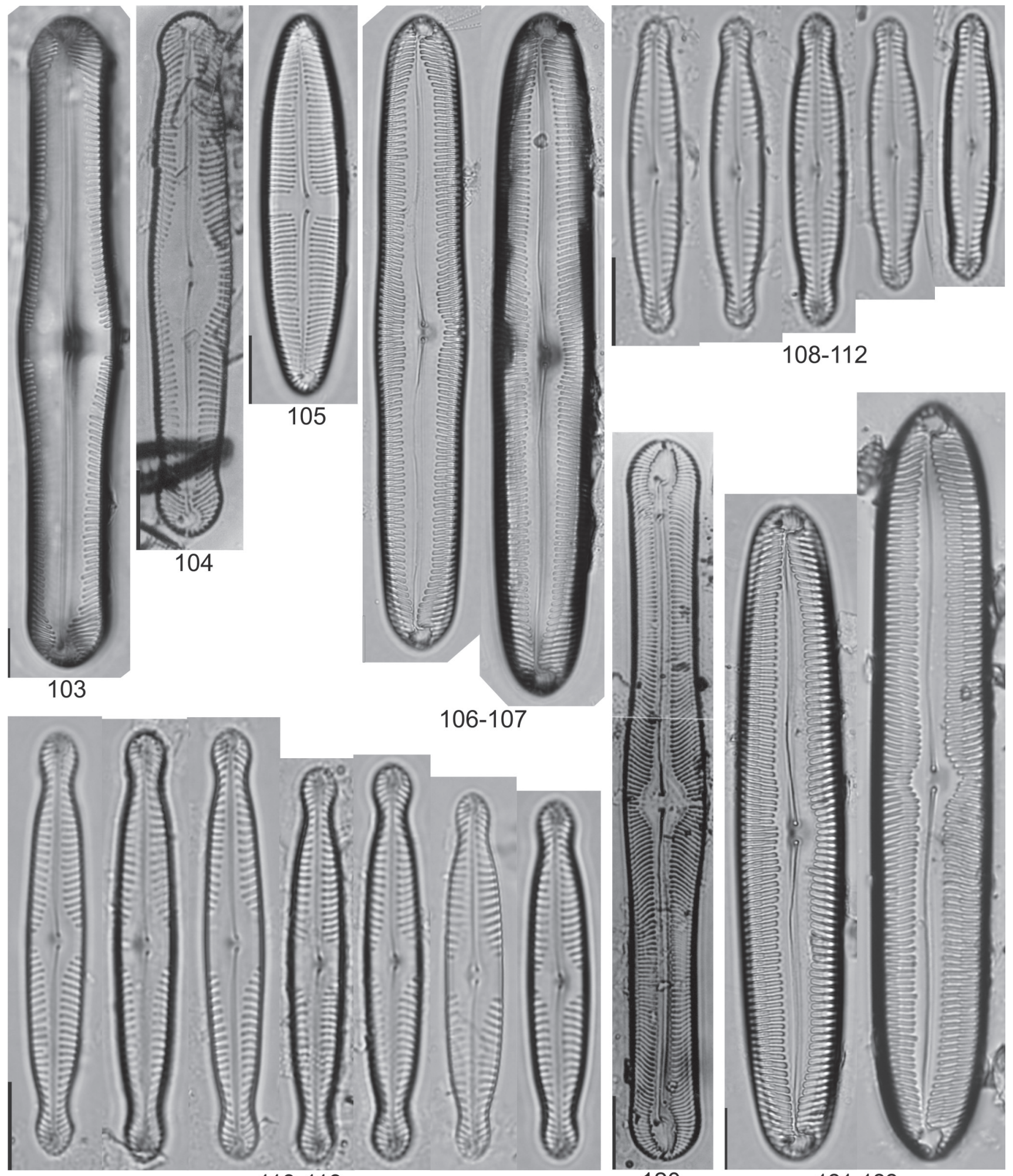

113-119

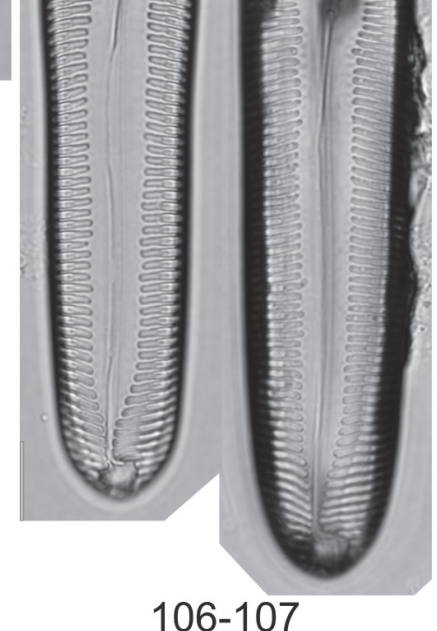


salinidade (estações 1, 2, 3, e 4) e durante períodos de maré baixa. Analisando a semelhança entre a flórula determinada em amostras perifíticas e planctônicas, 23 táxons foram comuns (46\%), sendo 16 e 11, respectivamente, exclusivos de cada amostra. Em outubro/03, segunda e última coleta, constatou-se um incremento de $40 \%$ no número de espécies de Pinnulariaceae do Guaraguaçu. Provavelmente, devido ao maior número de amostras coletadas na ocasião.

Aproximadamente $44 \%$ dos novos registros para o estado foram representados por apenas um exemplar, salientandose a importância de uma amostragem espacial e temporal abrangente, garantindo a constatação dos táxons mais raros.

O elevado número de novos registros de Pinnulariaceae para o estado registrado no estudo da flórula do Guaraguaçu, pode ser justificado pela recente publicação das revisões do gênero Pinnularia. Baseado em espécies na maioria européias e algumas de zonas tropicais, $\operatorname{Krammer}(1992,2000)$ propôs mais de 150 espécies e variedades novas, várias desmembradas de espécies amplamente divulgadas e comuns em ambientes paranaenses, como é o caso dos complexos P. microstauron, $P$. divergens e $P$. gibba. A reidentificação de materiais paranaenses presentes em trabalhos realizados antes das revisões do gênero foi dificultada, principalmente, pela total ausência de ilustrações ou por não haver representação da variação morfológica das espécies dos complexos acima mencionados, mesmo quando os autores comentaram as variações nas descrições dos táxons apresentados. A reidentificação foi possível no caso de $P$. gibba, exemplar único, citado e ilustrado por Bittencourt-Oliveira (2002) e Moura \& Bittencourt-Oliveira (2004), que na realidade correspondia a $P$. maculata, sendo este o registro anterior da espécie para o estado. Salienta-se que a documentação das espécies de diatomáceas por fotografia é uma importante ferramenta para os taxonomistas, uma vez que possibilita a reidentificação dos materiais.

\section{Agradecimentos}

À Coordenação de Aperfeiçoamento de Pessoal de Nível Superior/ CAPES pela concessão de bolsa a primeira autora e ao CNPq, pela bolsa de produtividade em pesquisa à segunda autora.

\section{Referências bibliográficas}

Barber, H.G. \& Harworth, E.Y. 1981. A Guide to the Morphology of the Diatom Frustule. Freshwater Biological Association. Cumbria, Ambleside.

Brassac, N.M. \& Ludwig, T.A.V. 2006. Diatomáceas da Bacia do rio Iguaçu, Paraná, Brasil: Pinnularia e Caloneis. Hoehnea 33(2): 127-142.

Bittencourt-Oliveira, M.C. 2002. A comunidade fitoplanctônica do rio Tibagi: uma abordagem preliminar de sua diversidade. Pp. 373-402. In: M.E. Medri et al. (eds.). A bacia do rio Tibagi. Londrina, M.E.Medri.

Cleve, P.T. 1894. Synopsis of the naviculoid diatoms. Part I. Kongliga Svenska Vetenskaps-Akademiens Handlingar 26: 1-194.

Cleve, P.T. 1895. Synopsis of the Naviculoid diatoms. Part II. Kongliga Svenska Vetenskaps- Akademiens Handlingar 27: 31-220.

Contin, L.F. 1990. Contribuição as estudo das diatomáceas (Chrysphyta, Bacillariophyceae) na região de captação d'água do rio Iguaçu (SANEPAR), em Curitiba, Estado do Paraná, Brasil. Estudos de Biologia (24): 5-95.
Costa, J.C.F. \& Torgan, L.C. 1991. Análise taxonômica de diatomáceas (Bacillariophyceae) do lago da Universidade Federal de Juiz de Fora, Minas Gerais, Brasil. Iheringia 41: 47-81.

Delgado, S.M. \& Souza, M.G.M. 2007. Diatomoflórula perifítica do rio Descoberto - DF e GO, Brasil, Naviculales (Bacillariophyceae): Diploneidineae e Sellaphorineae. Acta Botanica Brasilica 21(4): 767-776.

Fürstenberger, C.B. \& Valente-Moreira, I.M. 2000. Diatomáceas (Bacillariophyta) perifíticas da Lagoa Tarumã, Ponta Grossa, Paraná, Brasil. 1. Bacillariophycidae (exceto Eunotiaceae). Insula (29): 25-65.

Hendey, N.I. 1964. An introductory account of the smaller algae of British coastal waters: Part V. Bacillariophyceae (Diatoms). London, Her Majesty's Stationery Office.

Hustedt, F. 1930. Bacillariophyta (Diatomeae). In: A. Pascher (ed.). Die Süsswasser- Flora Mitteleuropas 10(2): 1-466.

Krammer, K. 1992. Pinnularia eine Monographie der europäichen Taxa. Bibliotheca Diatomologica 26: 1-353. Diatomologica 18: 1-877.

Krammer, K. 2000. The genus Pinnularia. Diatoms of Europe 1: 1-703.

Krammer, K. \& Lange-Bertalot, H. 1986. Bacillariophyceae: Naviculaceae. In: H. Ettl, J. Gerloff, H. Heynig, D. Mollenhauer (eds.). Süßwasserflora von Mitteleuropa 2, parte 1. New York, G. Fischer.

Lozovei, A.L. \& Luz, E. 1976. Diptera culicidae em Curitiba e arredores. II. Alimentação. Arquivos de Biologia e Tecnologia 19: 43-84.

Ludwig, T.A.V., Bigunas, P.I.T., Neiva, T.F., Coquemala, V. \& Piccinini, C. 2005. Diatomáceas (Ochrophyta) dos lagos do Jardim Botânico, Curitiba, Paraná. Pp. 301-323. In: Anais da X Reunião Brasileira de Ficologia. Bahia 2004. Rio de Janeiro, Museu Nacional, série livros, n. 10.

Mann, D.G. 2001. A discussion of Caloneis and related genera. Diatom 17: $29-36$.

Metzeltin, D. \& Lange-Bertalot, H. 1998. Tropical diatoms of the South America I. Iconografia Diatomologica 5: 1-695.

Metzeltin, D. \& Lange-Bertalot, H. 2007. Tropical diatoms of the South America II. Iconografia Diatomologica 18: 1-877.

Metzeltin, D.; Lange-Bertalot, H. \& García-Rodriguez, F. 2005. Diatoms of Uruguay - Compared with other taxa from South America and elsewhere. Iconographia Diatomologica 15: 1-736.

Metzeltin, D.; Lange-Bertalot, H. \& García-Rodriguez, F. 2005. Diatoms of Uruguay - Compared with other taxa from South America and elsewhere. Iconographia Diatomologica 15: 1-736.

Momoli, D.M.M. 1967. Contribuição ao estudo das diatomáceas do tanque do Senegaglia, São José dos Pinhais, Estado do Paraná, Brasil. Pp. 3346. In: Anais do Congresso da Sociedade Botânica do Brasil. Porto Alegre 1964. Rio Grande do Sul, UFRGS, n. 15.

Moreira-Filho, H. \& Momoli, D.M.M. 1966. Diatomáceas em alguns focos larvários de anofelinos de Curitiba (Paraná - Brasil). Boletim da Universidade Federal do Paraná, Botânica (15): 1-6.

Moreira-Filho, H. \& Valente-Moreira, I.M. 1981. Avaliação taxonômica e ecológica das diatomáceas (Bacillariophyceae) epífitas em algas pluricelulares obtidas nos litorais dos estados do Paraná, Santa Catarina e São Paulo. Boletim do Museu Botânico Municipal 47:1-17.

Moura, A.N. \& Bittencourt-Oliveira, M.C. 2004. Diatoms (Bacillariophyceae) of the Tibagi river, southern Brazil. Algological Studies 112:73-87.

Procopiak, L.K., Ferandes, L.F. \& Moreira-Filho, H. 2006. Diatomáceas (Bacillariophyta) marinhas e estuarinas do Paraná, Sul do Brasil: lista de espécies com ênfase em espécies nocivas. Biota Neotropica 6(3): http://www.biotaneotropica.org.br/v6n3/pt/abstract?inventory+ bn02306032006 (acesso em 02/03/2009).

Rocha, A.C.R. \& Bicudo, C.E.M. 2008. Criptógamos do Parque Estadual das Fontes do Ipiranga, São Paulo, SP. Algas, 25: Bacillariophyceae (Naviculales: Pinnulariaceae). Hoehnea 35(4): 597-618.

Rodrigues, L. 1991. Naviculaceae (Bacillariophyceae) nas lagoas do horto florestal Dr. Luiz Teixeira Mendes, município de Maringá, Paraná, Barsil. Revista UNIMAR 13(2): 273-298.

Round, F.E.; Crawford, R.M. \& Mann, D.G. 1990. The Diatoms: biology and morphology of the genera. New York, Cambridge University Press.

Rumrich, U.; Lange-Bertalot, H. \& Rumrich, M. 2000. Diatoms of the Andes. Iconographia Diatomologica 9: 1-673.

Schmidt, A. et al. 1874-1959. Atlas der Diatomaceen-Kunde. R. Reisland, Leipzig. Taf. 1-212 (A. Schmidt); Taf. 213-216 (M. Schmidt); Taf. 
217-240 (F. Fricke); Taf. 241-244 (H. Heiden); Taf. 245-246 (O. Müller); Taf. 247-256 (F. Fricke); Taf. 257-264 (H. Heiden); Taf. 265-268 (F. Fricke); Taf. 269-472 (F. Hustedt).

Simonsen, R. 1974. The diatom plankton of the Indian Ocean Expedition of R/V "Meteor", 1964-65 "Meteor" Forschungsergbnisse, Reihe D-Biologie (19): 1-66.

Souza, M.G.M. \& Moreira-Filho, H.M. 1999. Diatoms (Bacillariophyceae) of two aquatic macrophyte banks from Lagoa Bonita, Distrito Federal,
Brasil, II: Navicula sensu lato and Pinnularia. Bulletin du Jardin Botanique National de Belgique 67: 279-288.

Tavares, B. \& Valente-Moreira, I.M. 2000. Diatomoflórula do lago de Cascavel, município de Cascavel, estado do Paraná, Brasil. Hoehnea 27(1): 1-24.

Torgan, L.C., Becker, V. \& Prates, H.M. 1999. Checklist das diatomáceas (Bacillariophyceae) de ambientes de águas continentais e costeiros do Estado do Rio Grande do Sul. Iheringia, Série Botânica 52: 89-144.

Versão eletrônica do artigo em www.scielo.br/abb e http://www.botanica.org.br/acta/ojs 